\title{
Stimulation of TLR2 and TLR4 differentially skews the balance of T cells in a mouse model of arthritis
}

\author{
Shahla Abdollahi-Roodsaz, ${ }^{1}$ Leo A.B. Joosten, ${ }^{1}$ Marije I. Koenders, ${ }^{1}$ Isabel Devesa, ${ }^{1}$ \\ Mieke F. Roelofs, ${ }^{1}$ Timothy R.D.J. Radstake, ${ }^{1}$ Marleen Heuvelmans-Jacobs, ${ }^{1}$ Shizuo Akira, ${ }^{2}$ \\ Martin J.H. Nicklin, ${ }^{3}$ Fátima Ribeiro-Dias, ${ }^{4}$ and Wim B. van den Berg ${ }^{1}$ \\ ${ }^{1}$ Rheumatology Research and Advanced Therapeutics, Department of Rheumatology, Radboud University Nijmegen \\ Medical Centre, Nijmegen, The Netherlands. '2Department of Host Defense, Research Institute for Microbial Diseases, Osaka University, \\ Osaka, Japan. ${ }^{3}$ University of Sheffield, Division of Genomic Medicine, Sir Henry Wellcome Laboratories for Medical Research, \\ Sheffield, United Kingdom. ${ }^{4}$ Instituto de Patologia Tropical e Saúde Pública, Universidade Federal de Goiás, Goiânia, Brazil.
}

TLRs may contribute to the progression of rheumatoid arthritis through recognition of microbial or hostderived ligands found in arthritic joints. Here, we show that TLR2 and TLR4, but not TLR9, are involved in the pathogenesis of autoimmune arthritis and play distinct roles in the regulation of $\mathrm{T}$ cells and cytokines. We investigated the involvement of TLR2, TLR4, and TLR9 in the progression of arthritis using IL-1 receptor antagonist-knockout $\left(\mathrm{IL}_{1 \mathrm{rn}^{-/}}\right)$mice, which spontaneously develop an autoimmune $\mathrm{T}$ cell-mediated arthritis. Spontaneous onset of arthritis was dependent on TLR activation by microbial flora, as germ-free mice did not develop arthritis. Clinical and histopathological evaluation of $I L 1 \mathrm{rn}^{-/-} \mathrm{Tlr} 2^{-/-}$mice revealed more severe arthritis, characterized by reduced suppressive function of Tregs and substantially increased IFN- $\gamma$ production by $\mathrm{T}$ cells. IL $1 \mathrm{rn}^{-/-} \mathrm{Tlr} 4^{-/-}$mice were, in contrast, protected against severe arthritis and had markedly lower numbers of Th17 cells and a reduced capacity to produce IL-17. A lack of Tlr 9 did not affect the progression of arthritis. While any therapeutic intervention targeting TLR2 still seems complicated, the strict position of TLR4 upstream of a number of pathogenic cytokines including IL-17 provides an interesting potential therapeutic target for rheumatoid arthritis.

\section{Introduction}

RA is an autoimmune disease manifested by chronic inflammation and cartilage and bone destruction in multiple joints. Etiopathology of RA has been subjected to intensive research, resulting in the knowledge that proinflammatory cytokines such as TNF- $\alpha$, IL-1, and IL-17 as well as T and B lymphocytes are implicated in the pathogenesis of RA; however, it is still not clear which mechanisms are involved in the initiation and regulation of cytokine production and lymphocyte activation.

The discovery of TLRs as essential components of the immune system has introduced new subjects to the field of research on the pathogenesis of autoimmune diseases. TLRs are primarily involved in innate immune response to microbial pathogens through recognition of conserved pathogen-associated molecular patterns (1); however, they also contribute to sterile inflammation by sensing the "danger signals," i.e., endogenous molecules that are generated during tissue damage or inflammation (2-4). Activation of TLRs forms an important bridge between innate and adaptive immunity by regulating the expression of costimulatory molecules on APCs to drive T cell activation and by creating a cytokine milieu to conduct the differentiation of T cells into the desired subset (5). In this context, activation of TLRs, for instance TLR4 and TLR9, is generally thought to induce a Th1 response by driving IL-12 production by DCs (6-8); however, TLR2

Nonstandard abbreviations used: Foxp3, Forkhead box P3; GATA3, GATA-binding protein 3; IL1rn, IL-1 receptor antagonist; T-bet, T box expressed in T cells; Teff, effector T cell.

Conflict of interest: The authors have declared that no conflict of interest exists. Citation for this article: J. Clin. Invest. 118:205-216 (2008). doi:10.1172/JCI32639. activation might induce a Th2-biased immune response, through production of IL-10 and IL-13, capable of aggravating experimental asthma (9-11). TLR2 has also been reported to trigger the proliferation of Tregs, which play a crucial role in the induction of tolerance to self antigens and protection against autoimmunity (12-14). On the other hand, direct TLR2 activation on Tregs may cause a transient loss of suppressive function in these cells, a mechanism aimed to promote the antibacterial immune response during infection $(15,16)$. Activation of TLR4 is important for the survival of pathogenic Th17 cells through induction of IL-23 production by DCs (17); and, finally, TLR9 ligand CpG DNA inhibits $\mathrm{CD} 4{ }^{+} \mathrm{CD} 25^{+}$Treg-mediated suppression of the effector T cells $(18,19)$.

TLR ligands of microbial origin, such as bacterial DNA and peptidoglycans as well as Epstein-Barr virus, cytomegalovirus, and parvovirus, have repeatedly been found in joints of patients with RA, and several investigators have implicated bacterial or viral infections as initiating factors of the disease (20-24). In addition, the presence of endogenous TLR ligands such as fibronectin fragments and heat shock proteins, mainly activating TLR4 has been demonstrated in rheumatoid synovium (25-27). Since both microbial and hostderived TLR ligands are present in arthritic joints, these receptors may contribute to the initiation as well as the chronic progression of RA. The idea of the involvement of TLRs in RA is supported by enhanced expression of TLR2, $-3,-4$, and -7 in synovial lining and elevated TLR2 expression in CD16 blood monocytes and synovial macrophages of RA patients (28-31). Recently, Sacre et al. demonstrated that the spontaneous production of proinflammatory cytokines and matrix metalloproteinases by RA synovial membrane cells is inhibited by overexpression of dominant-negative forms of 
A

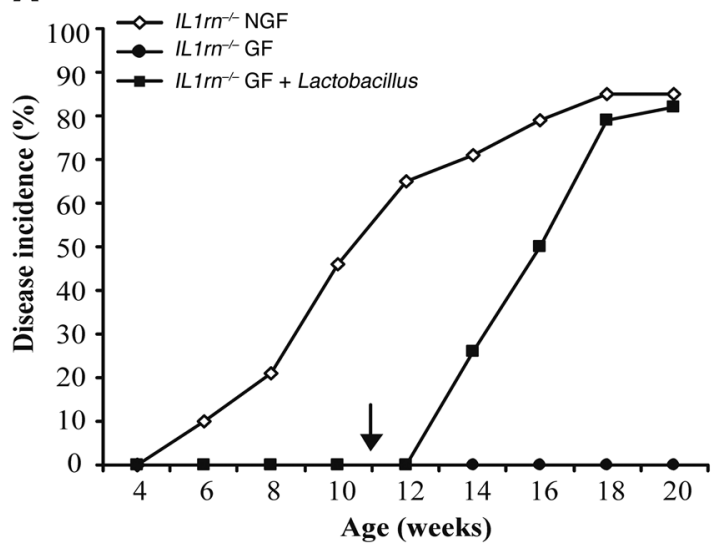

C

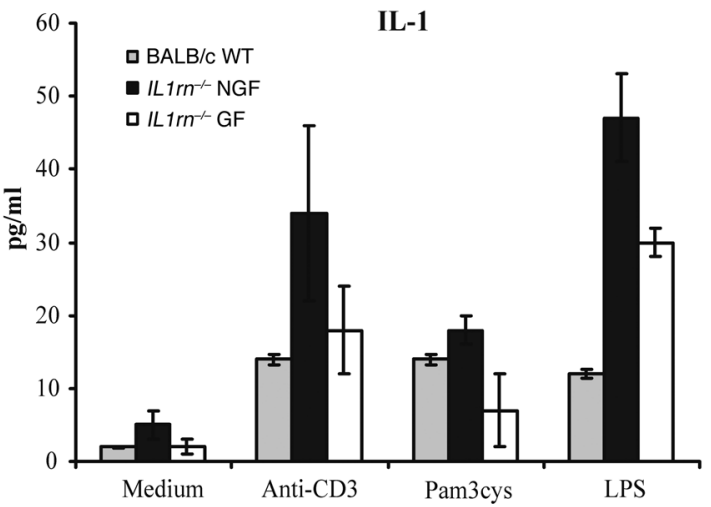

B

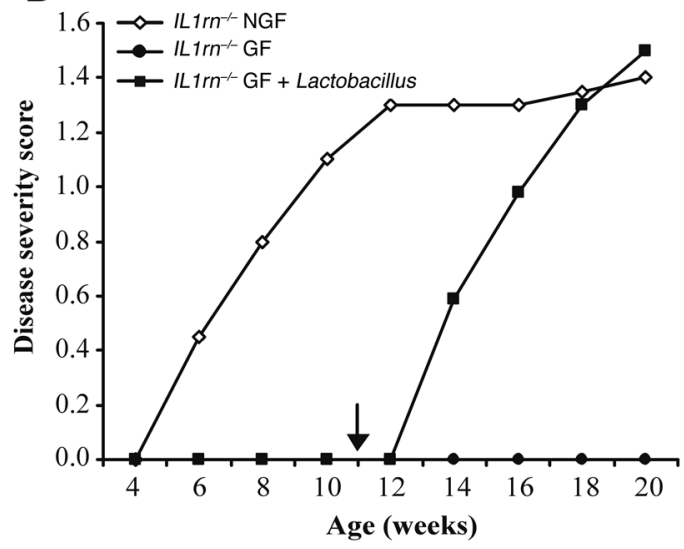

D

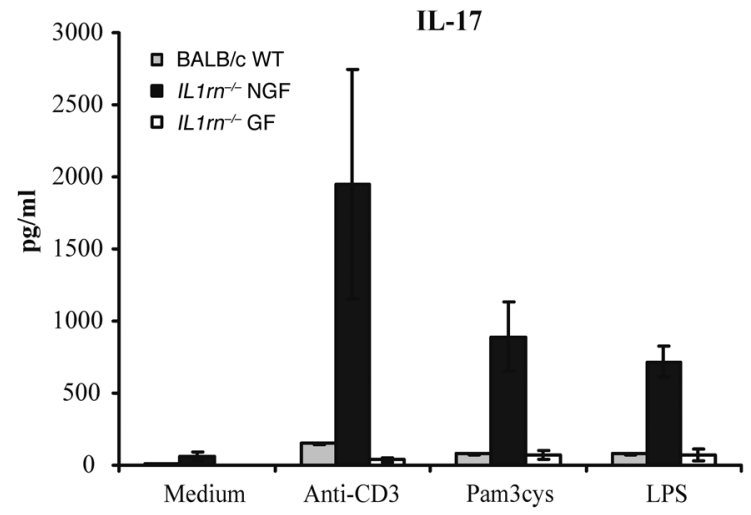

Figure 1

Effect of microbial status of $I L 1 \mathrm{rn}^{-1-}$ mice on the development of arthritis and cytokine response to TCR and TLR stimulations. The incidence (A) and severity (B) of arthritis are completely abolished in germ-free (GF) $I L 1 \mathrm{rn}^{-/-}$mice, and infection of GF mice with Lactobacillus (arrows) leads to the same disease expression as in non-germ-free (NGF) animals. Arthritis severity was scored on a scale from 0 to 2 for each paw; $n \geq 6$ per group. (C and D) Splenic lymphocytes $\left(2 \times 10^{5}\right)$ were stimulated with plate-coated anti-CD3 $(2 \mu \mathrm{g} / \mathrm{ml})$, Pam3Cys (100 ng/ml), or LPS $(200 \mathrm{ng} / \mathrm{ml})$ for 72 hours. IL-1 (C) and IL-17 (D) were measured using Luminex multianalyte technology (see Methods). Data are expressed as mean \pm SD and are representative of 2 independent experiments.

MyD88 and Mal, 2 essential adaptor molecules in signaling through TLR2 and TLR4 (32). This finding indicates that activation of TLR2 or TLR4 or both by endogenous ligands drives the spontaneous production of proinflammatory mediators by RA synovium.

In the present study, we investigated the involvement of TLR2, TLR4, and TLR9 in initiation and progression of arthritis using IL-1 receptor antagonist-deficient $\left(\mathrm{IL}_{\mathrm{rrn}} \mathrm{r}^{--}\right)$mice, which spontaneously develop an autoimmune $\mathrm{T}$ cell-mediated arthritis due to excessive IL-1 signaling $(33,34)$. Development of arthritis in these mice relies on pathogenesis by TNF- $\alpha$ and IL-17 (34-36). Here, we report that TLR2 and TLR4, but not TLR9, are involved in the expression of autoimmune arthritis in $\mathrm{ILIrn}^{-/-}$model. $\mathrm{IL}_{\mathrm{rnn}}^{-/-}$mice lacking Tlr2 showed an enhancement of clinical and histopathological scores of arthritis, whereas $\mathrm{IL} 1 \mathrm{rn}^{-/-} \mathrm{Tlr} 4^{-/-}$mice were protected against severe disease. We show that TLR2 downregulates the progression of arthritis through control of function of Tregs and regulation of IFN- $\gamma$-producing Th1 cells. TLR4, in contrast, contributes to more severe disease by modulating the Th17 cell population and IL-17 production. Furthermore, we demonstrate that endogenous TLR4 ligands are present in RA synovial fluid and drive the spontaneous production of cytokines in synovial tissue.

\section{Results}

Spontaneous onset of arthritis in IL1 $1 \mathrm{rn}^{-/-}$mice is abrogated in the absence of microbial flora. IL1 $\mathrm{rn}^{-/-}$mice develop spontaneous arthritis due to excessive IL-1 signaling. Since IL-1 receptor and TLRs share the signaling pathway, TLR activation might also function as a direct driving force behind the arthritis development in $\mathrm{IL}_{\mathrm{rn}}^{-/-}$mice or could drive arthritis indirectly by inducing IL-1. To investigate the involvement of pathogen-associated molecular patterns delivered by microbial flora in the development of spontaneous arthritis in $\mathrm{IL} 1 \mathrm{rn}^{-/-}$mice, germ-free $\mathrm{IL} 1 \mathrm{rn}^{-/-}$mice were generated and observed for macroscopic manifestations of arthritis. Germ-free animals showed no signs of arthritis during 20 weeks of follow-up, whereas age- and sex-matched non-germfree animals started to develop arthritis from the age of 5 weeks. At the age of 18 weeks, more than $80 \%$ of non-germ-free $1 \mathrm{~L}^{\mathrm{rm}} \mathrm{r}^{-/}$ mice exhibited signs of arthritis, mainly in the hind ankle joints (Figure 1, A and B).

Monocontamination of germ-free animals with only 1 indigenous microflora, Lactobacillus bifidus (37), resulted in rapid onset of arthritis that reached incidence rate and severity scores comparable to those in non-germ-free mice (Figure 1, A and B). 
A

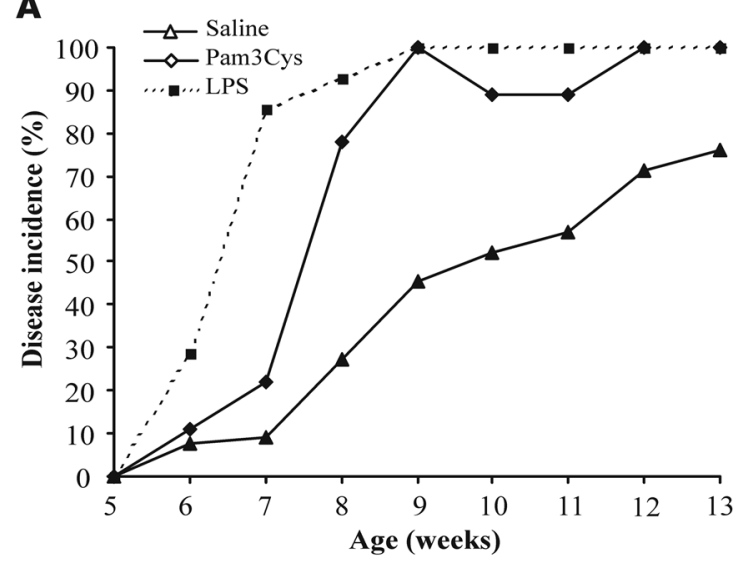

B

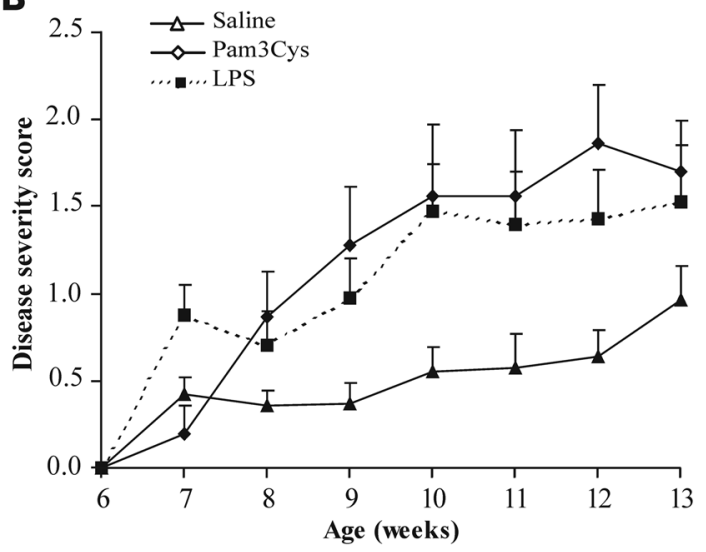

C

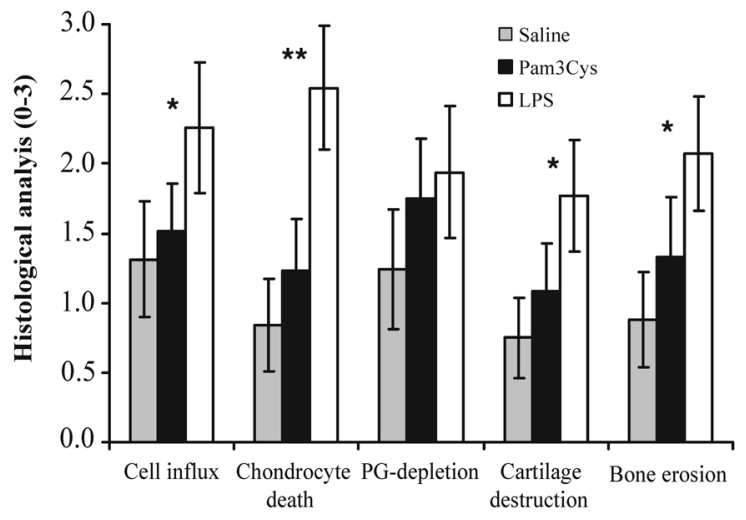

Figure 2

Effect of direct TLR2 and TLR4 stimulation on the development and pathogenesis of $I L 1 \mathrm{rn}^{-/-}$arthritis. Treatment of 5-week-old $I L 1 \mathrm{rn}{ }^{-/-}$mice with 1 i.p. injection of Pam3Cys (4 mg/kg body weight) or LPS (400 $\mu \mathrm{g} / \mathrm{kg}$ body weight) increased the incidence (A) and the macroscopic severity score (B) of arthritis. (C) Histological analysis of the ankle joints at 13 weeks of age expressed as mean \pm SEM on a scale from 0 to 3 . All parameters were scored by 2 observers blinded to the experimental protocol; $n=9$ mice per group. ${ }^{\star} P<0.05$ and ${ }^{* \star} P<0.01$.

IL1rn ${ }^{-1-}$ splenocytes exhibit an exaggerated response to TLR activation dependent on microbial status of mice. TLRs are the pivotal receptors that sense the presence of microbial agents. Therefore, we examined the effect of TLR activation on splenic lymphocytes of $I L 1 \mathrm{rn}^{-/-}$ mice of both germ-free and non-germ-free status. As shown in Figure 1, C and D, stimulation of lymphocytes using anti-CD3 $(2 \mu \mathrm{g} / \mathrm{ml})$ and TLR2 and TLR4 ligands (100 ng/ml Pam3Cys and $200 \mathrm{ng} / \mathrm{ml}$ LPS, respectively) resulted in much higher production of IL-1 $\beta$ and IL-17 by IL1rn-deficient cells from non-germ-free mice than by splenocytes from non-germ-free BALB/c WT mice. Higher IL-17 production by CD3-stimulated IL1 $\mathrm{rn}^{-/}$lymphocytes was in line with data reported previously (35). The germ-free status of $I L 1 \mathrm{rn}^{-/-}$animals resulted in a moderate decrease in IL-1 and a notable disruption of IL-17 production upon CD3 as well as TLR2 and TLR4 stimulation. IL-17 levels in germ-free mice were back to the WT levels, indicating that elevated production of this cytokine, which has been reported to be indispensable for the development of arthritis in $\mathrm{IL}_{\mathrm{rrn}}^{-/-}$mice (35), is completely dependent on previous confrontation with TLR agonists.

Acute stimulation of a single TLR results in aggravation of arthritis in $I L 1 \mathrm{rn}^{-/}$mice. Activation of TLRs induces the expression of a broad range of proinflammatory mediators. To examine the effect of activation of a single TLR on the spontaneous onset and severity of arthritis, we treated 6-week-old $I L 1 \mathrm{rn}^{-/-}$mice without arthritis with a 1-shot i.p. injection of Pam3Cys ( $4 \mathrm{mg} / \mathrm{kg}$ body weight) or LPS $(400 \mu \mathrm{g} / \mathrm{kg})$. Both TLR ligands accelerated the initiation of the disease symptoms, causing the maximal disease incidence at the early age of 9 weeks (Figure 2A). The arthritis severity score was also strongly enhanced even 7 weeks after injection (Figure 2B). Although the final outcome was similar in Pam3Cys- and LPStreated groups, LPS accelerated the disease faster than Pam3Cys. LPS injection also caused arthritis in forepaws. These observations indicate that a single-shot acute triggering of either TLR 2 or TLR4 enhances the expression of arthritis in $I \mathrm{~L} \mathrm{rn}^{-/}$mice.

On histology, LPS dramatically aggravated cell influx, chondrocyte death, and cartilage and bone destruction (Figure 2C). Inflammation was characterized by formation of villi and pannus tissue in synovium and the presence of both mononuclear and polymorphonuclear cells in the infiltrate. Despite the increase in clinical disease score by Pam3Cys, no significant changes were found on histology.

TLR2, TLR4, and TLR9 are differentially involved in the development and progression of arthritis in IL1rn-1- mice. To study the contribution of distinct TLRs to the development and the progression of autoimmune arthritis, we generated $I \mathrm{~L}_{\mathrm{rrn}}{ }^{-/-}$mice also lacking $\mathrm{Tlr}$, Tlr4, and Tlr9 genes on a BALB/c background. The development and progression of arthritis in ILIrn/Tlr double-deficient mice 


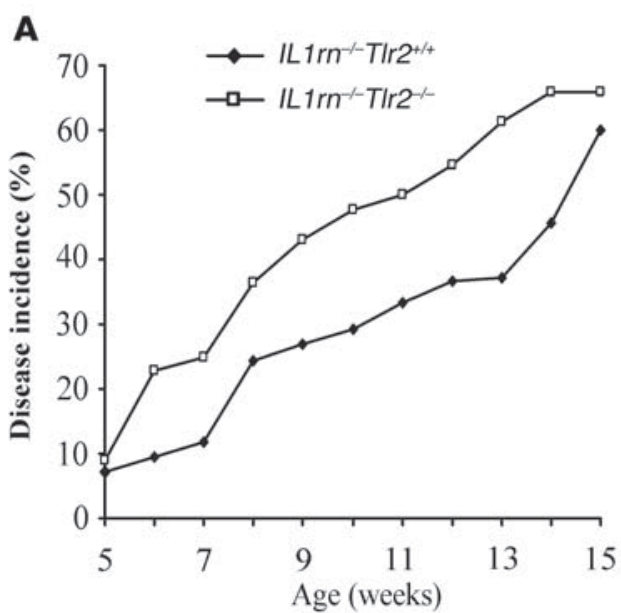

C

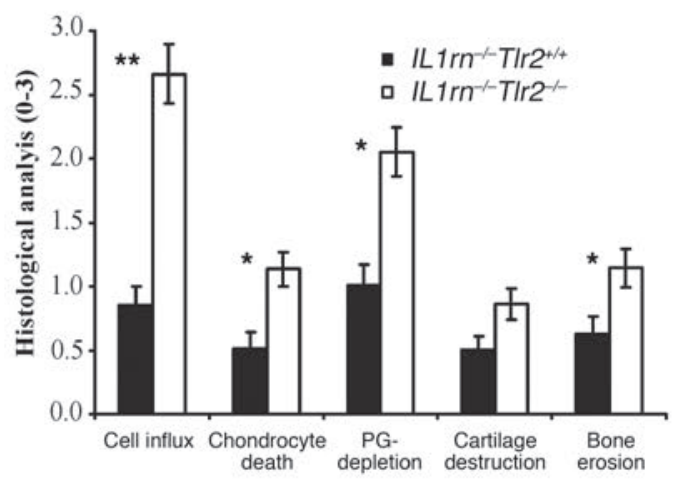

B

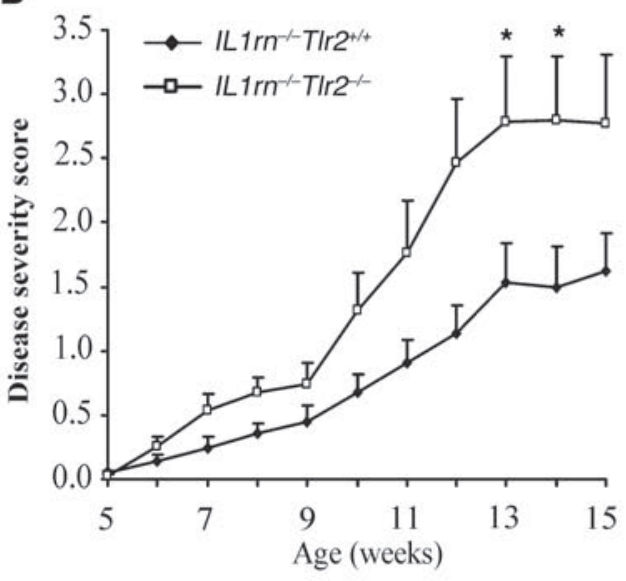

D

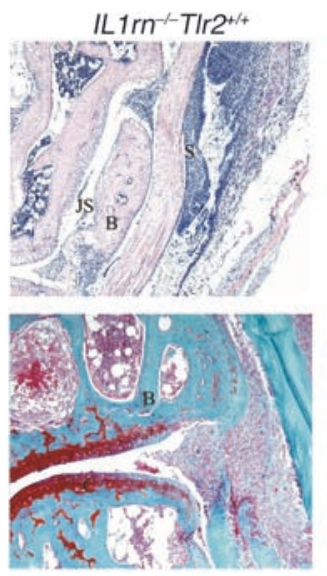

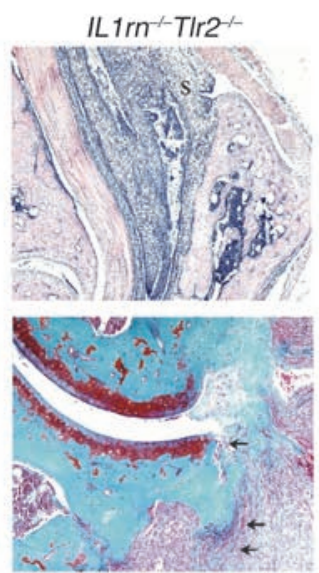

\section{Figure 3}

Higher severity and increased histopathology of $I L 1 \mathrm{rn}^{-1-}$ arthritis caused by T/r2 deficiency. Percentage incidence (A) and severity score (B) of arthri-

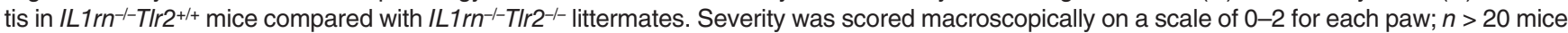
per group. (C) Histological assessment of the ankle joints at 15 weeks (mean \pm SEM) on a scale between 0 and 3 for each parameter; $n=14$ mice per group. (D) Representative histological images of ankle joints. Cell influx and chondrocyte death were scored on H\&E-stained (top row), and cartilage and bone damage (arrows) were scored on safranin O-stained (bottom row) tissue sections. PG depletion is apparent from loss of red staining. Original magnification, $\times 50$ for $\mathrm{H} \& \mathrm{E}$ and $\times 100$ for safranin $\mathrm{O}$ staining. $\mathrm{B}$, bone; $\mathrm{C}$, cartilage; JS, joint space; $\mathrm{S}$, synovium. ${ }^{*} P<0.05$ and ${ }^{* \star} P<0.01$.

were monitored over time and compared with those of age- and sex-matched $\mathrm{ILIrn}^{-/-} \mathrm{Tlr}^{+/+}$littermates to avoid variations in arthritis sensitivity based on differences in age, sex, and genetic background of the mice. These TLRs differentially contributed to the disease expression, since $T \operatorname{lr} 9$ deficiency in $I L 1 \mathrm{rn}^{-/-}$mice did not affect the disease incidence and severity (data not shown). Tlr $2^{-/-}$ mice developed more severe progressive arthritis, whereas Tlr4 deficiency protected $I \mathrm{~L} 1 \mathrm{rn}^{-/-}$mice from severe disease as described in the following sections.

Tlr2-deficient mice develop more severe arthritis than WT littermates. Although mice deficient for both IL1rn and Tlr2 had a slightly higher disease incidence compared with $\mathrm{IL}_{\mathrm{rrn}}{ }^{-/} \mathrm{Tlr} 2^{+/+}$littermates during the first weeks after onset, the incidence was similar at week 15 (Figure 3A). Interestingly, Tlr2 ${ }^{-/-}$mice developed more aggressive arthritis that reached a macroscopic severity score approximately $70 \%$ higher than the score in $\mathrm{Tl} 2^{+/+}$littermates (Figure 3B). On histological analysis of the ankle joints, $T l r 2^{-/-}$mice showed substantially higher amounts of infiltrated inflammatory cells, more chondrocyte cell death, and depletion of matrix proteoglycans (PGs) in cartilage and significantly increased bone erosion compared with that in $\mathrm{Tlr} 2^{+/+}$counterparts (Figure 3, C and D). This suggests that TLR2 activation in $I L 1 \mathrm{rn}^{-/-}$animals induces an antiinflammatory mechanism to partly control the progression of arthritis and to protect the joint from extreme damage.

Tlr2 deficiency leads to a shift in T cell balance from Th2 and T regulatory cells toward pathogenic Th1 cells. TLR2 has been reported to modulate some $\mathrm{T}$ cell subsets, such as Th2 and Tregs $(10,15,16,38)$. Therefore, we analyzed the mRNA expression of T box expressed in T cells (T-bet), GATA-binding protein 3 (GATA3), and Forkhead box P3 (Foxp3) - specific markers for Th1, Th2, and Tregs, respectively - in synovial biopsies of moderately inflamed ankle joints from 15 -week-old and in spleens of nonarthritic 6-week-old $\mathrm{ILIrn}^{-/-} \mathrm{Tlr} 2^{+/+}$and ILIrn ${ }^{-/-} \mathrm{Tlr}^{-/-}$mice. Quantitative real-time PCR indicated a clear shift in the balance between the antiinflammatory Th2/Treg and the proinflammatory Th1 markers in favor of the Th1 subset in ILIrn ${ }^{--}$Tlr2 ${ }^{-1-}$ synovium and spleen (Figure 4, A and B). Splenic T 

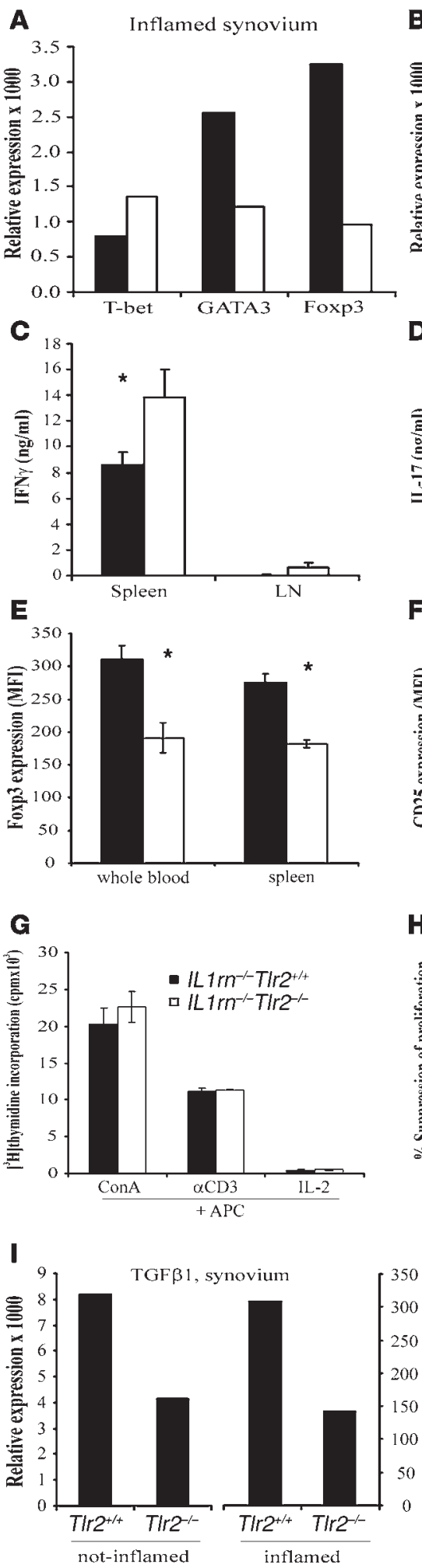

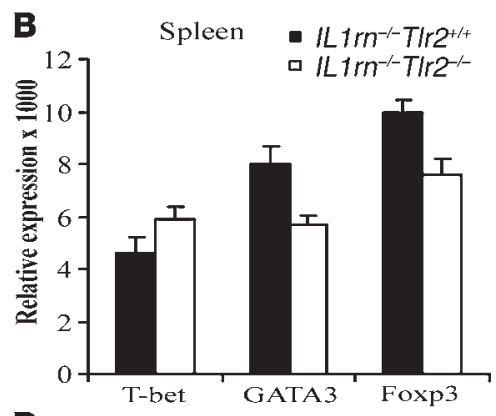

D
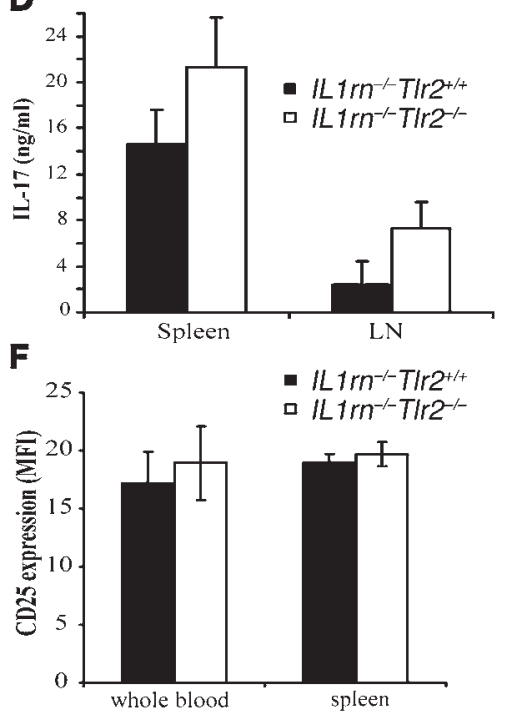

H

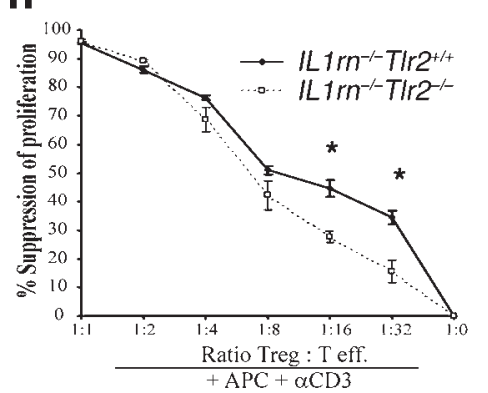

J

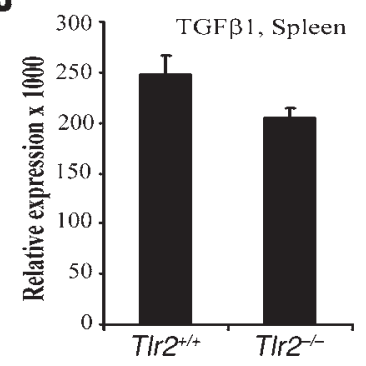

Figure 4

Influence of T/r2 deficiency on various Th cell subsets and the expression of related cytokines. mRNA expression of $T$ cell markers in inflamed synovium of the ankle joints (A) and spleens (B) of $I L 1 \mathrm{rn}^{-/-}$TIr2 ${ }^{-/-}$compared with IL $1 \mathrm{rn}^{-/-} \mathrm{TIr} 2^{+/+}$mice. Synovial biopsies were pooled from more than 5 joints of 15-week-old mice, and spleens were from 4 nonarthritic 6 -week-old mice. mRNA expression was measured by quantitative PCR. Relative mRNA expression compared with the housekeeping gene GAPDH $\left(2^{-\mathrm{dCt}} \times 1,000\right)$ is shown on the $y$ axis. IFN- $\gamma$ (C) and IL-17 (D) production by spleen and lymph node cells upon 72 hours stimulation with anti-CD3 $(0.5 \mu \mathrm{g} / 0.2 \mathrm{ml} / \mathrm{well})$ and anti-CD28 $(2 \mu \mathrm{g} / \mathrm{ml})$, measured by Luminex; results are mean \pm SEM from a representative experiment with $n>4$ mice per group. Protein expression of Foxp3 (E) and CD25 (F) on CD4+-gated CD25+Foxp3+ cells from whole blood and spleen of 15-week-old mice after correction for isotypematched IgG control; mean \pm SEM of $n=3$ from a representative experiment. ( $\mathbf{G}$ and $\mathbf{H}$ ) T cell suppression assay on splenic cells of $I L 1 \mathrm{rn}^{-/-} \mathrm{Tlr} 2^{+/+}$ and $I L 1 \mathrm{rn}^{-/-} \mathrm{TIr} 2^{-/-}$mice. (G) $\mathrm{CD} 4^{+} \mathrm{CD} 25^{-}$Teffs $(50,000$ cells/well) were stimulated with $1 \mu \mathrm{g} / \mathrm{ml}$ anti-CD3, $2 \mu \mathrm{g} / \mathrm{ml}$ concanavalin A, or $60 \mathrm{IU} / \mathrm{ml} \mathrm{IL-6}$ (negative control) in the presence of $50,000 /$ well irradiated CD4- cells as APCs. After 3 days, proliferation was measured by $\left[{ }^{3} \mathrm{H}\right]$ thymidine incorporation. (H) For suppression assays, cells were incubated with anti-CD3 and APCs in the presence of titrated numbers of Tregs (CD4+CD25+). Percent suppression was calculated relative to the cultures without Tregs. Measurements were performed in triplicate, and values shown are mean \pm SEM of 4 mice per group. mRNA expression of TGF- $\beta 1$ in noninflamed and inflamed ankle synovium (I) and spleen $(\mathbf{J})$, measured by quantitative PCR. Relative mRNA expression compared with GAPDH is shown. ${ }^{*} P<0.05$. cells from young IL1rn ${ }^{-/-}$Tlr2 ${ }^{-/-}$mice just prior to the disease onset produced substantially higher levels of IFN- $\gamma$ when stimulated with anti-CD3/anti-CD28 for 72 hours or with PMA/ionomycin for 5 hours (Figure 4C and data not shown). In addition, despite the similar Th17 cell subset on FACS analysis, IL1 $\mathrm{rn}^{-/-} \mathrm{Tlr} 2^{-/-} \mathrm{T}$ cells produced higher amounts of IL-17 upon these stimulations; how- ever, this increase was not statistically significant (Figure 4D and data not shown). Next, we analyzed the Treg population in whole blood and spleen using FACS analysis. Although the percentage of $\mathrm{CD} 4^{+} \mathrm{CD} 25^{+} \mathrm{Foxp}^{+}$Tregs was not altered by Tlr2 deficiency, the Tregs from both blood and spleen of $I L 1 \mathrm{rn}^{-/-} \mathrm{Tlr} 2^{-/-}$mice expressed significantly lower Foxp3 levels (Figure 4E). The expression of 

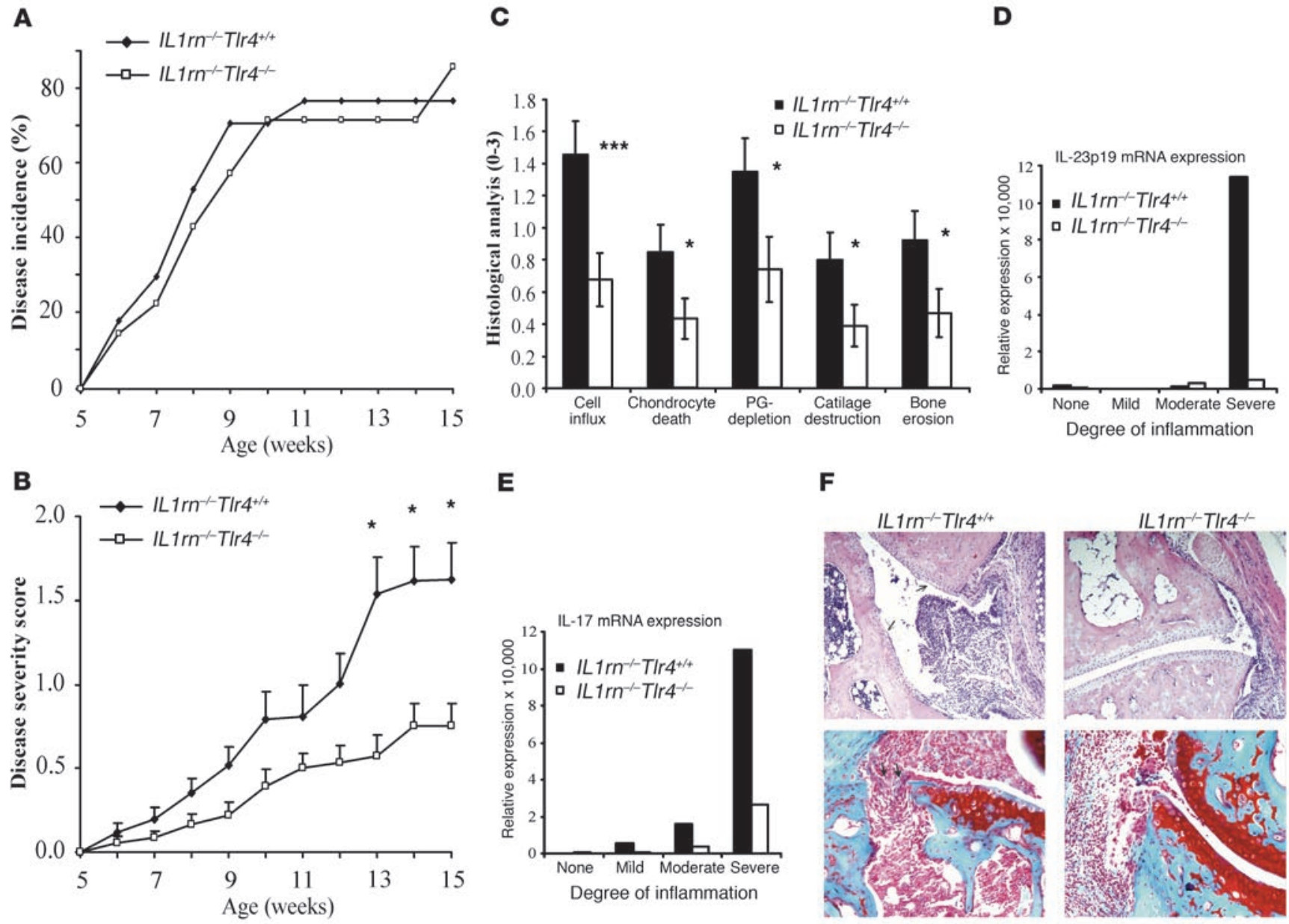

Figure 5

Lower severity and reduced histopathology of $I L 1 \mathrm{rn}^{-/-}$arthritis caused by T/r4 deficiency. Similar incidence (A) and reduced severity (B) of arthritis in $/ L 1 \mathrm{rn}^{-/-} \mathrm{Tlr} 4^{-/-}$as compared with $I L 1 \mathrm{rn}^{-/-} \mathrm{Tlr} 4^{+/+}$littermates during the first 15 weeks of age. Severity was scored on a scale of 0 to 2 for each paw; $n>20$ mice per group. (C) Histological assessment of the ankle joints at week 15 of age. Data are mean \pm SEM (scale 0-3) of 14 mice per group. mRNA expression of IL-23p19 (D) and IL-17A (E) in synovial biopsies of the ankle joints of 15-week-old mice selected according to the degree of inflammation. mRNA expression was measured by quantitative real-time PCR. Relative expression compared with GAPDH $\left(2^{-\mathrm{dCt}} \times 10,000\right)$ is shown. (F) Representative images of the ankle joints. Cell influx and chondrocyte death (arrows) were scored on H\&E-stained sections (top row), and cartilage and bone damage (arrows) were scored on safranin O-stained tissue sections (bottom row). Original magnification, $\times 100$ for H\&E and $\times 200$ for safranin $O$ staining. ${ }^{*} P<0.05$ and ${ }^{* * *} P<0.001$.

CD25 on Tregs remained unchanged (Figure 4F). Tregs from IL1 $\mathrm{rn}^{-/-} \mathrm{Tl} 2^{-/-}$mice had a functional defect in suppressing the antiCD3-stimulated proliferation of effector T cells (Teffs) at Treg/Teff ratios of 1:16 and 1:32 when compared with Tregs from $I L 1 \mathrm{rn}^{-/-}$ $\mathrm{Tlr}^{+/+}$matched littermates (Figure 4, G and H). Furthermore, the relative expression of the antiinflammatory mediator TGF- $\beta 1$, which is abundantly secreted by Tregs, was dramatically lower in both noninflamed and inflamed synovial tissue and in spleens of Tlr $2^{-/-}$mice (Figure 4, I and J). Reduced Foxp3 and TGF- $\beta$ expression together with defective Treg function and enhanced IFN- $\gamma$ production in $T l r 2^{-/}$mice suggest a skewed $\mathrm{T}$ cell balance that might explain enhanced arthritis in $I L 1 \mathrm{rn}^{-/-} \mathrm{Tlr} 2^{-/-}$mice.

Tlr4-deficient mice are protected against severe arthritis resulting from IL1rn gene deficiency. IL1 rn ${ }^{-/-} \mathrm{Tlr} 4^{+/+}$and ILIrn ${ }^{-/-} \mathrm{Tlr} 4^{-/-}$mice showed comparable disease incidence, indicating that the initiation of arthritis is independent of TLR4 activation (Figure 5A); however, the macroscopic inflammation scores of $I L 1 \mathrm{rn}^{-/-}$mice lacking Tlr4 were greatly reduced compared with those of IL1 $\mathrm{rn}^{-/-} \mathrm{Tlr}^{+/+}$littermates. The arthritis severity scores started to diverge from age 7-8 weeks, and the differences were most noticeable during the more-progressed chronic phase of the disease (13-15 weeks). Disease severity was reduced by $54 \%$ in Tlr4 $4^{-/-}$mice at 15 weeks (Figure $5 \mathrm{~B}$ ).

Histological examination of the ankle joints revealed that $\mathrm{Tlr}^{-/-}$ animals developed less progressive joint damage, since microscopic scores of inflammatory cell influx into the joint, chondrocyte death, cartilage PG depletion and destruction, and bone erosion were all significantly lower in $\mathrm{IL} 1 \mathrm{rn}^{-/-} \mathrm{Tlr} 4^{-/-}$mice compared with IL1 $\mathrm{rn}^{-/-} \mathrm{Tlr} 4^{+/+}$littermates (Figure 5C). In line with reduced joint damage in $\mathrm{Tlr}^{-/-}$mice, local mRNA expression of destruction-driving cytokines IL-23 and IL-17 was lower in synovial biopsies from IL $1 \mathrm{rn}^{-/-} \mathrm{Tlr} 4^{-/-}$compared with those of $\mathrm{IL} 1 \mathrm{rn}^{-/-} \mathrm{Tlr} 4^{+/+}$mice with equal inflammation score of the dissected joints (Figure 5, D and E). The expression of T cell markers T-bet, GATA3, and Foxp3 was 
A
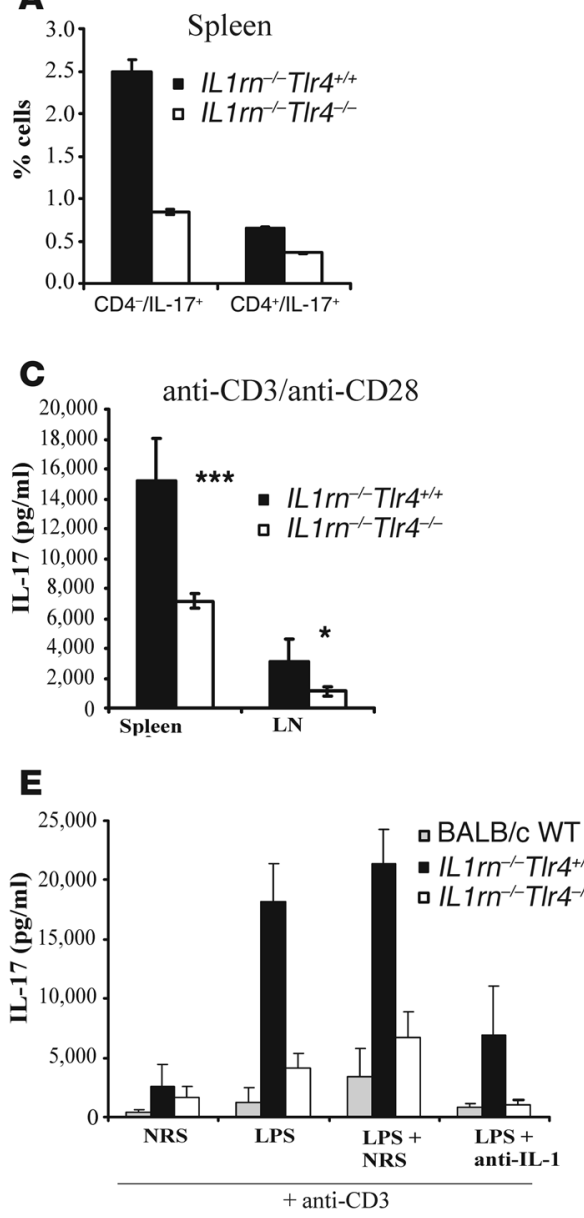

B

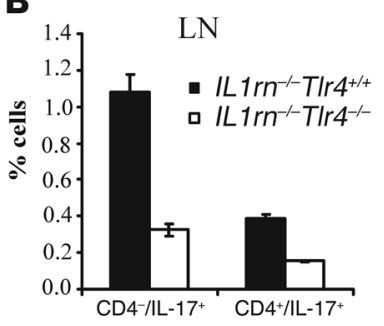

D

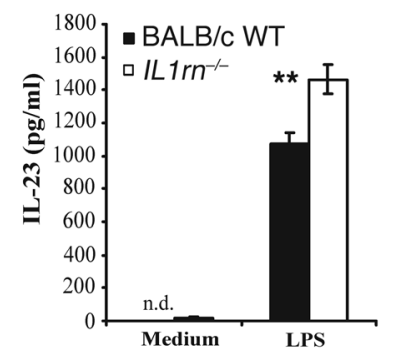

F

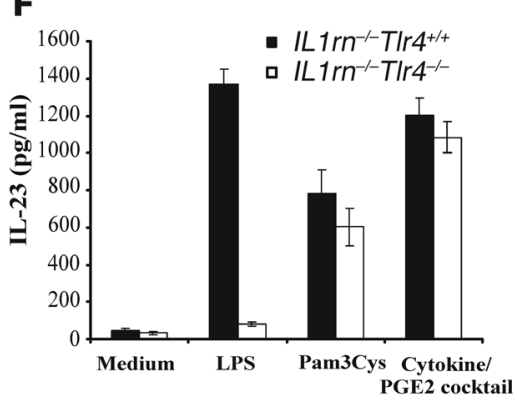

\section{Figure 6}

Decreased IL-17 in IL1rn- ${ }^{-/}$TIr4 ${ }^{-/-}$mice and IL-1mediated effects of TLR4 activation on IL-23/IL-17 production. (A-D and F) Spleens and lymph nodes from 5- to 6-week-old mice without arthritis were isolated and disrupted. $\mathrm{CD}^{+} \mathrm{T}$ lymphocytes were isolated using magnetic beads (MACS). (A and $\mathbf{B}$ ) Th17 FACS analysis following stimulation with PMA $(50 \mathrm{ng} / \mathrm{ml})$, ionomycin $(1 \mu \mathrm{g} / \mathrm{ml})$, and brefeldin $(1 \mu \mathrm{l} / \mathrm{ml})$ for 5 hours ; $n=4$. (C) IL-17 production by splenic and lymph node $\mathrm{T}$ cells upon stimulation with anti-CD3 $(0.5 \mu \mathrm{g} / 0.2 \mathrm{ml} /$ well $)$ and anti-CD28 $(2 \mu \mathrm{g} / \mathrm{ml})$ for 72 hours; measured by Luminex; $n \geq 6$. (D) TLR4 activation of bone marrow-derived DCs by $100 \mathrm{ng} / \mathrm{ml}$ LPS for 24 hours resulted in higher IL-23 production in IL $1 \mathrm{rn}^{-1-}$ cells compared with BALB/c WT. IL-23 was measured by ELISA; $n=10$. (E) TLR4 $(200 \mathrm{ng} / \mathrm{ml}$ LPS) plus anti-CD3 $(1 \mu \mathrm{g} / \mathrm{ml})$ activation of splenic T cells leads to higher IL-1-mediated IL-17 production in $I L 1 \mathrm{rn}^{-/-}$cells compared with WT cells, as measured by Luminex; $n=5$. (F) Bone marrow-derived DCs from IL $1 \mathrm{rn}^{-1-} \mathrm{TIr} \mathbf{4}^{-/-}$mice are not compromised in IL-23 production upon non-TLR4 stimulations. DCs were stimulated with $100 \mathrm{ng} / \mathrm{ml}$ LPS, $100 \mathrm{ng} / \mathrm{ml}$ Pam3Cys, or a cocktail of IL-1 $\beta$ (25 ng/ml), TNF- $\alpha$ (25 ng/ml), IL-6 (100 ng/ml), and PGE2 $(1 \mu \mathrm{g} / \mathrm{ml})$ for 24 hours; $n=4$ per group. Data are mean \pm SEM. NRS, normal rabbit serum. ${ }^{\star} P<0.05,{ }^{* \star} P<0.01$, and ${ }^{\star * \star} P<0.001$. similar in the 2 groups. Furthermore, there was no difference in mRNA expression of IFN- $\gamma$ or IL-10 on quantitative PCR. Figure 5F shows representative histological images of the ankle joints.

TLR 4 regulates the number of Th17 cells and the production of $I L-17$ in IL1 $\mathrm{rn}^{-/-}$mice. IL-17 has been described to play a crucial role in the spontaneous development of arthritis in $\mathrm{IL}_{1 \mathrm{rn}^{-/}}$mice (35). To clarify the mechanism by which TLR4 regulated the disease expression, we studied the effect of Tlr4 deficiency on the number of IL-17-producing T cells and on IL-17 production in $\mathrm{IL}_{\mathrm{rrn}}^{-/-}$mice. The percentage of $\mathrm{CD}^{+}$and $\mathrm{CD} 44^{-} \mathrm{Th} 17$ cells was measured in both $\mathrm{CD}^{+}$ splenocytes isolated using MACS technique and lymphocytes from popliteal and inguinal lymph nodes, before and after the onset of arthritis. FACS analysis revealed $50 \%$ reduction of CD $4{ }^{+} \mathrm{IL}-17^{+}$Th 17 cells in both spleen and lymph nodes of $\mathrm{Tlr}^{-/-}$mice, just before the expected onset of arthritis (5-6 weeks of age). The proportion of CD4- Th17 cells was also reduced, by approximately $70 \%$ (Figure 6, $A$ and $B)$. After the onset of arthritis (15 weeks of age), no clear difference in percentage of Th17 cells could be found; however, CD $4^{+}$ Th17 cells in popliteal and inguinal lymph nodes draining the site of inflammation expressed markedly lower levels of IL-17 (183.8 \pm 10.1 in $\mathrm{Tlr}^{+/+}$vs. $107.0 \pm 17.1$ in $\mathrm{Tlr}^{-/-}$mice; $P=0.0079$ ).

To confirm the involvement of TLR 4 activation in the regulation of IL-17 in $\mathrm{IL}_{\mathrm{rrm}}^{-/-}$mice, we measured the production of IL-17 protein by freshly isolated splenic and lymph node cells from 6-weekold mice after ex vivo stimulation with PMA/ionomycin or with anti-CD3/anti-CD28. In agreement with FACS data, IL1 rn-/-Tlr4-/- cells released significantly lower concentrations of IL-17 upon both stimulations compared with cells from their $\mathrm{IL} 1 \mathrm{rn}^{-/-} \mathrm{Tlr} 4^{+/+}$ littermates just before the initiation of arthritis (Figure $6 \mathrm{C}$ and data not shown). IL-10 and IFN- $\gamma$ concentrations were not different in these experiments. Lower IL-17 production by $\mathrm{T}$ cells from IL $1 \mathrm{rn}^{-/-} \mathrm{Tlr} 4^{-/-}$mice was also found in animals with established arthritis at 15 weeks of age, when the macroscopic severity score of arthritis was significantly lower in $\mathrm{Tlr} 4^{-/-}$mice (data not shown). Involvement of TLR 4 activation in regulating the Th17 subset of T cells and IL-17 production by these cells explained the finding that disease was less severe in $T l r 4^{-/-}$mice.

Regulation of Th17 cell number and IL-17 production by TLR4 is mediated through IL-1 and IL-23. IL-23 is a cytokine prominently involved in the survival of Th17 cells. IL-23 can be induced by TLR4 and has been shown to play a central role in the pathogenesis of spontaneous arthritis in $1 \mathrm{~L} 1 \mathrm{rn}^{-/-}$mice through induction of IL-17 (36). To investigate whether modulation of Th17 cell number and IL-17 production in $\mathrm{IL}_{\mathrm{rn}} \mathrm{r}^{-/-}$mice was mediated by IL-23, we studied the effect of TLR4 stimulation on the production of IL-23 by bone marrow-derived DCs from WT and IL1rn-/- mice. IL1rn gene deficiency did not interfere with the generation of CD $11 c^{+}$DCs (75\%-95\%) and the maturation of these cells by LPS, as measured by MHC class II and CD86 expression (data not shown); however, IL $1 \mathrm{rn}^{-/-}$DCs produced significantly more IL-23 than WT DCs upon stimulation with $100 \mathrm{ng} / \mathrm{ml}$ LPS for 24 hours (Figure 6D). Higher IL-23 production by APCs led to higher IL-17 production 
A

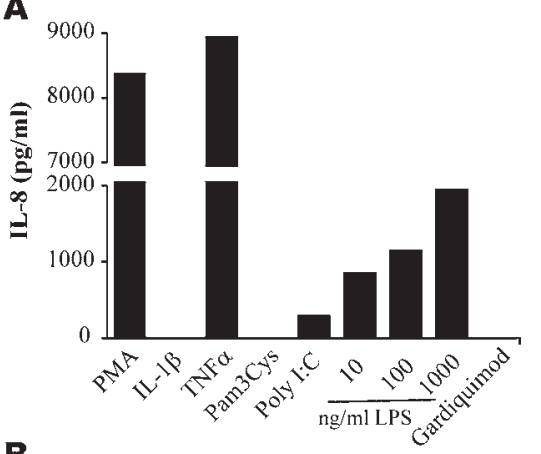

B
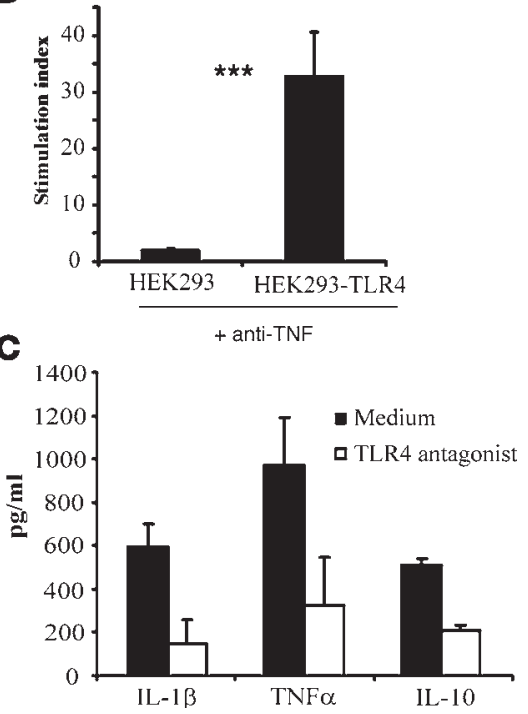

by $\mathrm{T}$ cells in total splenocyte culture (APCs plus T cells) from nondiseased $\mathrm{IL}_{\mathrm{rnn}}^{-/-}$mice stimulated with anti-CD3 in combination with LPS when compared with WT splenocyte culture (Figure 6E). IL-17 induction by TLR4 might also occur indirectly through IL-1, as IL-1 drives IL-23 production. Indeed, inhibition of IL-1 blocked the extremely high IL-17 production by IL $1 \mathrm{rn}^{-1-} \mathrm{T}$ cells upon CD3/ LPS stimulation (Figure 6E). IL1 $\mathrm{rn}^{-/}$-Tlr4-/- DCs were not compromised in IL-23 production, as they produced IL-23 levels comparable to those in $\mathrm{IL}_{\mathrm{rm}} \mathrm{rn}^{-/-} \mathrm{Tlr} 4^{+/+}$DCs when stimulated with non-TLR4 proinflammatory modulators (Figure 6F). These data indicate that TLR 4 controls the production of IL-17 by IL1 $1 \mathrm{rn}^{-/}$Th17 cells by inducing IL-23 and IL-1 production by $\mathrm{IL} 1 \mathrm{rn}^{-/-}$APCs.

Presence of endogenous TLR4 ligands in RA joints drives the spontaneous production of cytokines by $R A$ synovial tissue. To assess the clinical relevance of TLR 4 activation in RA patients, we investigated the presence of TLR4 ligands in synovial fluid from RA patients using HEK293 cells expressing TLR4. Cells were first tested for response to a number of proinflammatory mediators, including various TLR ligands. As shown in Figure 7A, HEK293-TLR4 cells produced IL-8 in a dose-dependent manner upon stimulation with LPS. Furthermore, they were highly stimulated by TNF- $\alpha$ but not by IL-1 $\beta$ and TLR2 and TLR7 ligands (Pam3Cys and Gardiquimod, respectively). HEK293-TLR4 cells also produced low concentrations of IL-8 upon TLR3 stimulation by Poly(I:C) (Figure 7A). When incubated with RA synovial fluid in combination with a soluble TNF receptor (Enbrel) to block the response to putative TNF- $\alpha$ present in the samples, HEK293-TLR4 cells produced

\section{Figure 7}

TLR4-mediated stimulation of cytokine production by rheumatoid synovial fluid and in synovial biopsies of RA patients. (A) HEK293-TLR4 cells were stimulated with PMA, IL-1 $\beta$, TNF- $\alpha$, and various TLR ligands as indicated in Methods. Mean IL-8 concentrations (Luminex assay) of triplicates are shown. (B) HEK293 and HEK293-TLR4 cells were stimulated with synovial fluid of RA patients in the presence of a TNF- $\alpha$ blocker (Enbrel; $100 \mathrm{ng} / \mathrm{ml}$ ) or remained unstimulated (medium control). IL-8 was measured in culture supernatants after 24 hours. Stimulation index over medium control of each cell line is shown on the $y$ axis; $n=7$. Data are mean \pm SEM. ${ }^{* * *} P<0.001$. (C) Synovial biopsies of RA patients were cultured ex vivo with or without TLR4 antagonist $(10 \mu \mathrm{g} / \mathrm{ml})$ for 24 hours. Experiments were performed in triplicate. The concentration of cytokines was measured using Luminex. Data are mean \pm SEM from 7 RA patients.

much higher concentrations of IL-8 compared with HEK293 cells without TLR4 (Figure 7B). This indicated the presence of endogenous TLR4 ligands capable of activating NF-KB in synovial fluid of RA patients, as these samples were previously shown to be endotoxin free in an assay based on the response of CHO-hTLR4-CD14 cells in combination with polymyxin B (data not shown). Next, we examined the effect of TLR4 inhibition on spontaneous production of cytokines by synovial tissue of RA patients. TLR4 antagonist partially inhibited the production of IL-1 $1 \beta$, TNF- $\alpha$, and IL-10 by RA synovium in ex vivo cultures (Figure 7C), showing the involvement of TLR 4 activation in this phenomenon.

\section{Discussion}

IL1 $\mathrm{rn}^{-1-}$ mice develop an autoimmune destructive arthritis that exhibits several characteristics of RA (33). Autoimmunity in these mice results from excessive IL-1 signaling due to the lack of natural IL-1 receptor antagonist. IL-1 contributes to autoantigen-specific $\mathrm{T}$ cell activation and antibody production through induction of CD40L and OX40 expression on T cells (36). IL-1 can also activate autoreactive $\mathrm{CD} 4^{+} \mathrm{T}$ cells by activating DCs (35). The $\mathrm{T}$ cell cytokines TNF- $\alpha$ and IL-17 are known to play crucial roles in $\mathrm{IL}_{1} \mathrm{mn}^{-/-}$ arthritis $(34,35)$, and IL-23 has recently been demonstrated to be the link between IL-1 and IL-17 (36). Furthermore, T cells from IL1 $\mathrm{rn}^{-1-}$ mice have been reported to produce higher amounts of IFN- $\gamma$ compared with WT T cells $(34,36)$. Despite the accumulating data on the complex cytokine network in this spontaneous model of arthritis, the initial trigger of cytokine production has not been elucidated before. Our data indicate that a general proinflammatory event, e.g., sensing the microbial flora through TLRs, may send the first signal to induce IL-1 production and drive the T cell-mediated onset of arthritis in $I L 1 \mathrm{rn}^{-/-}$mice, since $\mathrm{IL} 1 \mathrm{rn}^{-/-}$mice in germ-free conditions do not develop arthritis at all. In non-germ-free $\mathrm{IL}_{\mathrm{rm}} \mathrm{m}^{-/}$ mice, a single-shot acute TLR2 or TLR4 activation is enough to overstate the incidence and the severity of arthritis. This appeared to be a general phenomenon caused by a strong pulse of proinflammatory cytokines and was also observed upon injection of synthetic TLR3 and TLR7 ligands [Poly(I:C) and loxoribine, respectively] (S. Abdollahi-Roodsaz, unpublished observations); however, only LPS enhanced long-term histological damage. Exceptionally, systemic injection of a TLR9 ligand (stimulatory CpG ODN1826) did not affect the expression of arthritis, probably because of the different cytokine profile induced by TLR9. Studies in $\mathrm{IL}_{1 \mathrm{rn}^{-/}} \mathrm{Tl}^{-}{ }^{--}$mice clarified the role of distinct TLRs in fine-tuning the progression and chronicity of arthritis. TLR9 has been described to directly enhance the survival of activated murine $\mathrm{CD} 4^{+} \mathrm{T}$ cells and inhibit the sup- 
pressive properties of Tregs $(18,19,39)$. Although TLR9 activation has recently been implicated in other autoimmune diseases such as multiple sclerosis, possibly through its activation by endogenous "danger signals" (40), Tlr9 deficiency did not affect the incidence and the severity of $I \mathrm{~L}_{\mathrm{rrn}}^{-/-}$autoimmune arthritis. This suggests that there is no native TLR9 activation present in $\mathrm{IL}_{\mathrm{rrn}}^{-/-}$mice that could modulate the disease expression. Tlr2-deficient mice showed a higher disease incidence and developed a more aggressive form of arthritis. The observation that both application of a TLR2 ligand and Tlr2 deficiency result in aggravation of arthritis might seem contradictory at first glance; however, the expression pattern of TLR 2 and the diverse nature of cytokines induced by TLR 2 allow it to play a dual role depending on how and where it has been activated. Intraperitoneal injection of high-dose TLR2 ligand leads to the production of proinflammatory cytokines such as IL-1 $\beta$, IL-6, and TNF- $\alpha$, which are strong promoters of inflammation and are believed to be responsible for the aggravation of arthritis. On the other hand, TLR2 has been reported to induce a Th2-biased immune response capable of aggravating experimental asthma and to inhibit IFN- $\gamma$ production by LPS-stimulated PBMCs $(10,11$, 41). In addition, $T l r 2^{-/-}$mice have significantly lower number of Tregs due to lower IL-10 concentrations (12). Direct in vitro TLR2 activation on Tregs, a situation mimicking bacterial infection, has recently been shown to induce the expansion of Tregs accompanied by a transient loss of function, which is recovered after removal of TLR2 ligand $(15,16)$.

Here, we describe a shift in balance between various $\mathrm{T}$ cell subsets in IL1 $\mathrm{rn}^{-/-} \mathrm{Tlr} 2^{-/-}$mice characterized by reduced Th2 and Treg markers in spleen and locally within the joint and a seemingly enhanced Th1 marker in the joint. Consistently, IL1 rn ${ }^{-/-} \mathrm{Tlr} 2^{-/-} \mathrm{T}$ cells produced markedly higher amounts of IFN- $\gamma$ upon general and CD3-specific stimulations. Recent findings identified IL-17 as a crucial disease-promoting factor in autoimmune disorders and showed an inhibitory effect of IFN- $\gamma$ on Th17 development from naive T cells $(42,43)$; however, IL-17 production by effector and memory Th17 cells in the presence of IL-23 was not inhibited by IFN- $\gamma$. Therefore, in Tlr $2^{-/-}$mice, where TLR4 and IL-23 pathways are intact, committed Th 17 cells are expected to be resistant to suppression by IFN- $\gamma$. Interestingly, IL-17 production also repeatedly tended to be higher in $I L 1 \mathrm{rn}^{-/-} \mathrm{Tlr} 2^{-/-} \mathrm{T}$ cells, despite similar Th17 cell number on FACS analysis. Very recently, the presence of a new $\mathrm{T}$ cell subtype producing both IFN- $\gamma$ and IL-17, with more pathogenic characteristics compared with cells only producing IL-17, has been described in experimental autoimmune encephalomyelitis (44). The presence of a similar "Th1/Th17" subset has also been demonstrated in the gut of patients with Crohn disease (45). Therefore, IL-17 and IFN- $\gamma$ in Tlr2 $2^{-/-}$mice might theoretically have been produced by the same cell population.

An effect on the Treg population in IL1 $\mathrm{rn}^{-/-} \mathrm{Tlr} 2^{-/-}$animals was confirmed by the significant reduction in the expression of the transcription factor Foxp3. Foxp3 is considered the most specific marker for Tregs, and its expression directly correlates with the suppressor activity of these cells, irrespective of CD25 expression $(46,47)$. Attenuated Foxp3 expression abrogates the immune-suppressive, but not hypoproliferative, activities of Tregs and results in an aggressive autoimmune syndrome (48). TLR2 deficiency in $I L 1 \mathrm{rn}^{-1-}$ mice led to less Foxp3 expression and reduced suppressive activity of these cells (Figure 4). Furthermore, expression of TGF- $\beta 1$ was partially reduced in $T l r 2^{-/}$spleen and synovium. TGF- $\beta$ plays a complex role in $\mathrm{T}$ cell differentiation: in the absence of IL- 6 , it promotes the lineage commitment of naive T cells toward Tregs, while in the presence of IL-6, it promotes skewing of naive T cells toward the Th17 phenotype (49-52). In IL1rn-/- mice, the development of neither Tregs nor Th17 cells was affected, since the number of both cell subsets remained unaltered. Alternatively, TGF- $\beta$ is also produced by some Tregs and is one of the mechanisms of the suppressive function of these cells (53). In this context, lower TGF- $\beta$ expression is in line with reduced Foxp 3 expression and defective function of Tregs in Tlr2 $2^{-/}$mice; however, whether the reduced Treg function in these mice is a consequence of lower TGF- $\beta$ production requires further investigation. The major function of Tregs is to inhibit other $\mathrm{T}$ cells from mounting an immune attack against self components and to prevent autoimmunity (54, 55). Therefore, the exaggerated autoimmune arthritis in $\mathrm{Tlr} 2^{-/-}$ animals is a net result of reduced suppressive Treg function and enhanced IFN- $\gamma$-producing Th1 cells.

Tlr4-deficient IL $1 \mathrm{rn}^{-/-}$mice, in contrast to Tlr2 $2^{-/-}$animals, were protected against severe arthritis and long-term joint destruction. We demonstrate here that TLR4 promotes joint inflammation and both cartilage and bone destruction by driving the highly pathogenic Th17 cells through induction of IL- 1 and IL-23. Both $\mathrm{CD}^{+}$and $\mathrm{CD}^{-}\left(\mathrm{CD}^{+}\right) \mathrm{IL}-17-$ expressing cells were present in $\mathrm{IL} \mathrm{rn}^{-/-}$mice and were reduced upon Tlr4 deficiency. Therefore, both subpopulations are considered to contribute to IL-17 production in $I L 1 \mathrm{rn}^{-/-}$ mice. Inhibition of IL-1 blocked TLR4-mediated IL-17 production. IL-1 $\beta$ promotes, together with TNF- $\alpha$, Th17 cell commitment from naive T cells, a process principally driven by IL- 6 and TGF- $\beta$ (49-51). Conditioned medium of TLR4-stimulated DCs has been shown to replace IL-6, IL-1 $\beta$, and TNF- $\alpha$ in Th17 cell differentiation (51). In IL1rn-deficient coculture of APCs and T cells, IL-1 contributes to approximately $70 \%$ of IL-17 production (Figure $6 \mathrm{E}$ ). The remaining IL-17 production is attributable to other LPS-induced cytokines produced by APCs, in particular IL-6. IL-23 by itself does not contribute to Th17 differentiation; however, since the presence of already differentiated Th17 cells in the splenic cell culture of $I{\mathrm{~L} 1 \mathrm{rn}^{-/-}}^{-1}$ mice is presumable, LPS-induced IL-23 might also be involved by favoring the expansion and maintenance of these cells. IL-1 and IL-17 determine the inflammatory and destructive character of several experimental models of arthritis (56-58). Furthermore, IL-17 is expressed in synovial sublining of RA patients (59) and inhibits collagen synthesis and bone formation in synovium and bone explants of RA patients (60). Therefore, the function of TLR4 upstream of IL-1 and IL-17 might have important consequences for the treatment of RA. Our previous studies emphasized the beneficial effects of specific TLR4 inhibition using a TLR4 antagonist in both collagen-induced and $\mathrm{ILIrn}^{-/-}$arthritis (61).

The exact source of TLR ligands contributing to the modulation of arthritis is not clear. Enhanced IFN- $\gamma$ production in $\mathrm{Tl} / 2^{-/-}$mice and reduced IL-17 production in Tlr $4^{-/}$mice could be detected before any visible joint inflammation. This suggests that TLR ligands of microbial origin, not the endogenous ligands, are possibly involved in this phase. On the other hand, the similar disease incidence and the more pronounced suppression of disease severity in $\mathrm{Tlr} 4^{-/-}$compared with $\mathrm{Tlr} 4^{+/+}$mice during the chronic late phase of arthritis suggest the involvement of endogenous TLR4 ligands generated by inflammation and tissue damage. Several endogenous ligands have been described for both TLR2 and TLR4 $(4,62,63)$; however, in some pathologic situations, such as ischemia/reperfusion injury or hemorrhagic shock, only TLR4, but not TLR2, has been found to sense tissue damage (64-66). In the 
present study, we show that synovial fluid of RA patients contains ligands capable of activating TLR4 on HEK293 cells. Inhibition of the spontaneous production of proinflammatory cytokines by synovial tissue of RA patients using a TLR4 antagonist underlines the clinical relevance of TLR4 activation in RA. TLR4 is mainly expressed on APCs, and its activation indirectly modulates Th17 cells through induction of proinflammatory cytokines such as IL-1 and IL-6. TLR4 expression on T cells has also been demonstrated; however, direct TLR4 stimulation of naive T cells does not induce Th17 cell differentiation (51). The contribution of TLR2 in $\mathrm{IL}_{1 \mathrm{rn}^{-/}}$arthritis is more likely to be a direct effect on T cells, since Tregs express functional TLR2, stimulation of which affects the expansion and function of these cells $(15,16)$ (Figure 4). Another remarkable point concerning the difference in regulation of arthritis by TLR 2 and TLR 4 is that the Th1 profile with high IFN- $\gamma$ levels in $\mathrm{Tlr} 2^{-/}$mice did not aggravate cartilage destruction, whereas IL-17 clearly determined the severity of cartilage destruction as indicated by less cartilage damage in $\mathrm{Tlr} 4^{-/-}$mice.

The differential and complex roles of TLR2 and TLR4 in defining the cytokine environment and $\mathrm{T}$ cell differentiation have great implications for future interventions in (auto)immune disorders. Considering the dual role of TLR2, therapeutic interventions on TLR2 still seem complicated and would warrant additional studies. In comparison with TLR2, TLR4 appears to be a more interesting target, because it consistently plays a proinflammatory role and will probably be easier to interfere with. Further focus on the nature of TLR ligands and the kinetics of TLR-mediating immune regulation in distinct disease conditions is of high importance.

\section{Methods}

Animals. WT BALB/c mice were purchased from Charles River Laboratories. IL $1 \mathrm{rn}^{-/-}$mice on a BALB/c background were generated as described previously (67). $T l r 2^{-/-}$mice were on a C57BL/6 background, and $T l r 4^{-/-}$and $\mathrm{Tlr} 9^{-/-}$mice were backcrossed from $\mathrm{C} 57 \mathrm{BL} / 6$ backgrounds onto BALB/c for 5 generations. We crossed the mice (further) onto the arthritis-susceptible strain $\mathrm{BALB} / \mathrm{c}$ mice until they were backcrossed for at least 8 generations. Subsequently, $\mathrm{IL}_{\mathrm{rnn}}^{-/-}\left(\mathrm{Tlr}^{+/+}\right)$and $\mathrm{Tlr}^{-/-}\left(\mathrm{IL}_{\mathrm{Lrn}}^{+/+}\right)$mice were crossed, and offspring heterozygous for both IL-1Rn and each TLR were intercrossed to obtain homozygous $\mathrm{IL}_{1 \mathrm{rn}^{-/-}}$mice that were either $\mathrm{Tlr}^{+/+}$or $\mathrm{Tlr}^{-/}$. The mice were housed in filter-top cages, and water and food were provided ad libitum. Germ-free mice were housed in isolators under controlled environmental and nutritional conditions. Lactobacillus bifidus was introduced into the germ-free animals at the age of 11 weeks by pouring $10 \mathrm{ml}$ of the pure broth cultures in 10A medium (developed for selection of Lactobacilli) on the food as described previously (37). Age- and sex-matched littermates were used in all experiments. Animal studies were approved by the Institutional Review Board of Radboud University Nijmegen Medical Centre and were performed according to the appropriate codes of practice.

Treatment of animals and clinical evaluation of arthritis. For in vivo TLR stimulation, 6-week-old $\mathrm{IL}_{\mathrm{rnn}}^{-/-}$mice without arthritis were treated using a single i.p. injection of the TLR2 ligand Pam3Cys ( $4 \mathrm{mg} / \mathrm{kg}$ body weight; EMC Microcollections) or the TLR4 ligand LPS (400 $\mu \mathrm{g} / \mathrm{kg}$; Sigma-Aldrich). Control mice received $0.2 \mathrm{ml}$ sterile saline.

Development of arthritis was macroscopically scored using an arbitrary scoring system as follows: 0 , no redness and swelling; 0.25 , slight redness; 0.5 , slight redness and swelling; $0.75-1$, mild redness and swelling; $1.25-1.5$, moderate redness and swelling; $1.75-2$, severe redness and swelling. Only the hind joints were scored, as forepaws developed arthritis very seldom.

Histology. For histological assessment of arthritis, total ankle joints from 15 -week-old mice were isolated and fixed for 4 days in $4 \%$ formaldehyde, then decalcified in $5 \%$ formic acid and embedded in paraffin. Tissue sections of $7 \mu \mathrm{m}$ were stained using $\mathrm{H} \& \mathrm{E}$ to study the inflammatory cell influx and chondrocyte death or using safranin $\mathrm{O}$ to determine proteoglycan depletion and cartilage and bone destruction. Each parameter was scored on a scale from 0 to 3 by 2 independent observers in a blinded manner. At least 4 junctions per tissue section and 4 sections per ankle joint were scored.

Generation and maturation of bone marrow-derived DCs. Bone marrow cells were isolated from 6- to 8-week-old $I L 1 \mathrm{rn}^{-/-}$mice without arthritis and cultured for 9 days with $3 \mathrm{ng} / \mathrm{ml} \mathrm{GM-CSF}(\mathrm{R} \& \mathrm{D})$. The DC phenotype was controlled by measuring the CD11c expression on FACS using anti-CD11c-APC antibodies (BD Biosciences - Pharmingen). For DC maturation and IL-23 production, $1 \times 10^{6} \mathrm{immature}$ DCs were incubated with $100 \mathrm{ng} / \mathrm{ml}$ purified E. coli LPS, $100 \mathrm{ng} / \mathrm{ml}$ Pam3Cys or the Jonuleit cocktail (68) consisting of IL-1 $\beta(25 \mathrm{ng} / \mathrm{ml})$, TNF- $\alpha(25 \mathrm{ng} / \mathrm{ml})$, IL- $6(100 \mathrm{ng} / \mathrm{ml})$, and PGE2 $(1 \mu \mathrm{g} / \mathrm{ml})$ for 24 hours. DC maturation was determined by measuring the upregulation of MHC class II and CD86 markers using anti-MHCII-FITC (BMA Biomedicals) and anti-CD86-PE (BD Biosciences - Pharmingen) FACS antibodies.

Isolation, culture, and stimulation of lymphocytes. Spleens and popliteal and inguinal lymph nodes were isolated and disrupted. Erythrocytes in spleens were lysed. Then, the cell suspension was enriched for $\mathrm{T}$ cells by allowing APCs to adhere to plastic culture flasks for 45 minutes. For APC-T cell cocultures, total splenocytes were used without performing any adherence step. For some experiments described in Results, T cells were isolated using the magnetic cell sorting (MACS) technique (Miltenyi Biotec) following the manufacturer's guidelines prior to stimulation. Cells were cultured in RPMI-1640 (Gibco; Invitrogen) supplemented with 5\% FCS, 1 mM pyruvate, and $50 \mathrm{mg} / \mathrm{l}$ gentamicin at $37^{\circ} \mathrm{C}, 5 \% \mathrm{CO}_{2}$ with the following stimulations: plate-coated anti-CD3 $(2 \mu \mathrm{g} / \mathrm{ml}$ or $0.5 \mu \mathrm{g} /$ well as indicated in Figure legends; R\&D), anti-CD28 ( $2 \mu \mathrm{g} / \mathrm{ml}$; BD Biosciences), PMA (50 ng/ml; SigmaAldrich), ionomycin (1 $\mu \mathrm{g} / \mathrm{ml}$; Sigma-Aldrich), the Golgi-traffic inhibitor brefeldin (1 $\mu \mathrm{l} / \mathrm{ml}$; BD Biosciences), Pam3Cys (100 ng/ml; EMC Microcollections), and LPS (200 ng/ml, double-purified using the phenol-water extraction method at our laboratory; Sigma-Aldrich). For IL-1 blocking, polyclonal rabbit anti-mouse IL- $1 \alpha$ and IL- $1 \beta$ antibodies (69) were used in combination. Final concentrations were 20 and $80 \mu \mathrm{g} / \mathrm{ml}$ for IL- $1 \alpha$ and IL- $1 \beta$, respectively. Anti-IL-1 serum contained $10 \mathrm{mg} / \mathrm{ml}$ purified antibodies, and $1 \mu \mathrm{g}$ of these antibodies was shown to neutralize up to $100 \mathrm{pg}$ IL-1 in the NOB-1 bioassay (70). Normal rabbit serum (NRS) was used as control. Anti-IL-1 sera and NRS were added to the cells shortly before addition of LPS. Incubation time was 72 hours for anti-CD3 and anti-CD28; 5 hours for PMA, ionomycin, and brefeldin; and 24 hours for Pam3Cys and LPS.

Tcell proliferation and suppression assay. Splenic MACS-isolated CD $4^{+} \mathrm{CD} 25^{-}$ Teffs $(50,000$ cells/well) were stimulated with $1 \mu \mathrm{g} / \mathrm{ml}$ anti-CD3, $2 \mu \mathrm{g} / \mathrm{ml}$ concanavalin $\mathrm{A}$, or $60 \mathrm{IU} / \mathrm{ml}$ IL-6 (negative control) in the presence of 50,000/well irradiated (30 Gy) CD4- cells as APCs. After 3 days, proliferation was measured by $\left[{ }^{3} \mathrm{H}\right]$ thymidine incorporation. For suppression assays, cells were incubated with anti-CD3 and APCs in the presence of titrated numbers of Tregs $\left(\mathrm{CD} 4^{+} \mathrm{CD} 25^{+}\right)$. Percentage of suppression was calculated relative to the cultures without Tregs.

Measurement of cytokines. Cytokine concentrations (except those of IL-23) in culture supernatants were determined using Luminex multianalyte technology. The Bioplex system in combination with multiplex cytokine kits (Bio-Rad) was used. IL-23 concentrations were measured using ELISA (eBioscience) following the manufacturer's instructions.

FACS analysis of T cells. Th17 cells in spleen and lymph nodes were stained using anti-CD4-APC, then washed with FACS buffer (PBS plus 1\% BSA) and fixed in PBS containing $2 \%$ paraformaldehyde. Subsequently, cells were stained with anti-IL-17-PE in FACS buffer containing $0.1 \%$ saponin. Tregs in whole blood and spleen, in which erythrocytes were lysed, were stained with anti-CD4-APC and anti-CD25-FITC. Then, cells were fixed and 
permeabilized using Fix/Perm buffer (eBioscience) and stained with antiFoxp3-PE. An appropriate isotype-matched control antibody was used in all FACS analyses. All antibodies were from BD Biosciences - Pharmingen except anti-Foxp3 (eBioscience). Cells were analyzed on a FACSCalibur flow cytometer using CellQuest software (BD Biosciences - Pharmingen).

Isolation of RNA from spleen and synovial biopsies. Six-week-old mice without arthritis were sacrificed by cervical dislocation, and spleens were isolated and stored separately in liquid $\mathrm{N}_{2}$ until RNA isolation ( $n=4$ per group). Synovial biopsies were isolated from the ankle joints with various degrees of macroscopic inflammation by dissecting synovium around and between ankle bones using microscissors. Synovium samples with the same inflammation score (5-6 joints each) were pooled within each group and kept separately to avoid any influence of differences in the degree of inflammation on mRNA expression of the genes of interest.

Total RNA was isolated in $1 \mathrm{ml}$ TRIzol (Sigma-Aldrich), then precipitated with isopropanol, washed with $70 \%$ ethanol, and dissolved in water. RNA was treated with DNase and subsequently reverse transcribed into cDNA using oligo-dT primers and MMLV reverse transcriptase.

Quantitative real-time PCR. Quantitative real-time PCR was performed using the ABI Prism 7000 Sequence Detection System (Applied Biosystems) for quantification with SYBR Green and melting curve analysis. Primer sequences were as follows: for GAPDH (housekeeping gene), 5'GGCAAATTCAACGGCACA-3' (forward) and 5'-GTTAGTGGGGTCTCGCTCTG-3' (reverse); for IL-23p19, 5'-CCAGCGGGACATATGAATCTACT-3' (forward) and 5'-CTTGTGGGTCACAACCATCTTC-3' (reverse); for IL-17A, 5'-CAGGACGCGCAAACATGA-3' (forward) and 5'-GCAACAGCATCAGAGACACAGAT-3' (reverse); for TGF- $\beta 1,5^{\prime}$-GCAGTGGCTGAACCAAGGA-3' (forward) and 5'-AAGAGCAGTGAGCGCTGAATC-3' (reverse); for T-bet, $5^{\prime}$-CAACAACCCCTTTGGCAAAG-3' (forward) and 5'-TCCCCCAAGCAGTTGACAGT-3' (reverse); for GATA3, 5'-AGAACCGGCCCCTTATCAA-3' (forward) and 5'-AGTTCGCGCAGGATGTCC-3' (reverse); for Foxp3, 5'-AGGAGAAGCTGGGAGCTATGC-3' (forward) and 5'-GGTGGCTACGATTGCCAGCAA-3' (reverse).

PCR conditions were as follows: 2 minutes at $50^{\circ} \mathrm{C}$ and 10 minutes at $95^{\circ} \mathrm{C}$, followed by 40 cycles of 15 seconds at $95^{\circ} \mathrm{C}$ and 1 minute at $60^{\circ} \mathrm{C}$, with data collection during the last 30 seconds. For all PCRs, SYBR Green Master Mix (Applied Biosystems) was used in the reaction. Primer concentrations were $300 \mathrm{nM}$. The $\mathrm{C}_{\mathrm{t}}$ value of the gene of interest was corrected for the $\mathrm{C}_{\mathrm{t}}$ of the reference gene GAPDH to obtain the $\Delta \mathrm{C}_{\mathrm{t}}$. Relative mRNA expression was calculated by 2 to the power of $-\Delta C_{t}$. Quantitative PCR analysis for each sample was performed in duplicate, and melting curves were run for each PCR.

Assessment of endogenous TLR4 ligands in synovial fluid and synovial tissue of RA patients. HEK293 and HEK293-TLR4 cells were purchased from
InvivoGen and cultured according to the manufacturer's guidelines. For stimulations, $5 \times 10^{4}$ cells/well were used in flat-bottom, 96-wells plates. HEK293-TLR 4 cells were stimulated with PMA (50 ng/ml; SigmaAldrich), hIL-1 $\beta$ and hTNF- $\alpha$ (both $20 \mathrm{ng} / \mathrm{ml} ; \mathrm{R} \& D)$, Pam3Cys $(10 \mu \mathrm{g} / \mathrm{ml}$; ECM Microcollections), Poly(I:C) $(25 \mu \mathrm{g} / \mathrm{ml}$; InvivoGen), LPS (10, 100, and $1000 \mathrm{ng} / \mathrm{ml}$; Sigma-Aldrich), and Gardiquimod (1 $\mathrm{gg} / \mathrm{ml}$; Invivogen) for 24 hours, and IL- 8 was measured in culture supernatants. For stimulation with synovial fluid of RA patients, $10 \mu \mathrm{l}$ synovial fluid was added into $200 \mu \mathrm{l}$ culture medium containing $100 \mathrm{ng} / \mathrm{ml}$ TNF blocker (Enbrel; Amgen). IL-8 was measured in culture supernatants, and stimulation index over the medium control was calculated. Spontaneous production of cytokines was measured upon 24 hours ex vivo culture of RA synovial biopsies ( $3 \mathrm{~mm}$ in diameter) incubated with or without $10 \mu \mathrm{g} / \mathrm{ml}$ Bartonella quintana LPS as TLR4 antagonist (61). Assays were performed in triplicate. All patients provided informed consent, and the Medical Ethics Committee of Radboud University Medical Centre Nijmegen approved the study protocol.

Statistics. Group measures are expressed as mean \pm SEM unless otherwise indicated. The statistical significance of differences between experimental groups was assessed using the Mann-Whitney $U$ test performed on GraphPad Prism 4.0 software (GraphPad Software Inc.). $P$ values of 0.05 or less were considered significant.

\section{Acknowledgments}

We are grateful to L. van den Bersselaar for genotyping the mice. We would like to thank B. Oppers-Walgreen, M. Helsen, and C. Arndtz for their support in in vivo studies and in tissue processing for histological analysis. We would also like to thank S. Veenbergen and $\mathrm{M}$. Bennink for their contribution in setting up the $\mathrm{T}$ cell proliferation assay. This work was supported by Dutch Arthritis Association grant 03-1-301. Fátima Ribeiro-Dias is a recipient of a postdoctoral fellowship supported by CAPES/Ministry of Education, Brazil.

Received for publication May 9, 2007, and accepted in revised form October 3, 2007.

Address correspondence to: Shahla Abdollahi-Roodsaz, Rheumatology Research and Advanced Therapeutics, Department of Rheumatology, Radboud University Nijmegen Medical Centre, PO Box 9101, 6500HB, Nijmegen, The Netherlands. Phone: 00-3124-3616451; Fax: 00-31-24-3540403; E-mail: s.abdollahi-roodsaz@ reuma.umcn.nl.
1. Akira, S., Uematsu, S., and Takeuchi, O. 2006. Pathogen recognition and innate immunity. Cell. 124:783-801.

2. Johnson, G.B., Brunn, G.J., Kodaira, Y., and Platt, J.L. 2002. Receptor-mediated monitoring of tissue well-being via detection of soluble heparan sulfate by Toll-like receptor 4. J. Immunol. 168:5233-5239.

3. Okamura, Y., et al. 2001. The extra domain A of fibronectin activates Toll-like receptor 4. J. Biol. Chem. 276:10229-10233.

4. Schaefer, L., et al. 2005. The matrix component biglycan is proinflammatory and signals through Toll-like receptors 4 and 2 in macrophages. J. Clin. Invest 115:2223-2233.

5. Re, F., and Strominger, J.L. 2001. Toll-like receptor 2 (TLR2) and TLR4 differentially activate human dendritic cells. J. Biol. Chem. 276:37692-37699.

6. Krieg, A.M. 2002. CPG motifs in bacterial DNA and their immune effects. Annu. Rev. Immunol. 20:709-760.

7. Reis e Sousa, G., et al. 1997. In vivo microbial stim- ulation induces rapid CD40 ligand-independent production of interleukin 12 by dendritic cells and their redistribution to T cell areas. J. Exp. Med. 186:1819-1829.

8. Trinchieri, G. 2003. Interleukin-12 and the regulation of innate resistance and adaptive immunity. Nat. Rev. Immunol. 3:133-146.

9. Agrawal, S., et al. 2003. Cutting edge: different Tolllike receptor agonists instruct dendritic cells to induce distinct Th responses via differential modulation of extracellular signal-regulated kinase-mitogen-activated protein kinase and c-Fos. J. Immunol. 171:4984-4989.

10. Dillon, S., et al. 2004. A Toll-like receptor 2 ligand stimulates Th2 responses in vivo, via induction of extracellular signal-regulated kinase mitogen-activated protein kinase and c-Fos in dendritic cells. J. Immunol. 172:4733-4743.

11. Redecke, V., et al. 2004. Cutting edge: activation of Toll-like receptor 2 induces a Th2 immune response and promotes experimental asthma.
J. Immunol. 172:2739-2743.

12. Netea, M.G., et al. 2004. Toll-like receptor 2 suppresses immunity against Candida albicans through induction of IL-10 and regulatory T cells. J. Immunol. 172:3712-3718.

13. Roncarolo, M.G., and Levings, M.K. 2000. The role of different subsets of $\mathrm{T}$ regulatory cells in controlling autoimmunity. Curr. Opin. Immunol. 12:676-683.

14. Sakaguchi, S., et al. 2006. Foxp3+ CD25+ CD4+ natural regulatory $\mathrm{T}$ cells in dominant self-tolerance and autoimmune disease. Immunol. Rev. 212:8-27.

15. Liu, H., Komai-Koma, M., Xu, D., and Liew, F.Y. 2006. Toll-like receptor 2 signaling modulates the functions of CD4+ CD25+ regulatory T cells. Proc. Natl. Acad. Sci. U. S. A. 103:7048-7053.

16. Sutmuller, R.P., et al. 2006. Toll-like receptor 2 controls expansion and function of regulatory $\mathrm{T}$ cells. J. Clin. Invest. 116:485-494.

17. Vanden Eijnden, S., Goriely, S., De Wit, D., Gold- 
man, M., and Willems, F. 2006. Preferential production of the IL-12(p40)/IL-23(p19) heterodimer by dendritic cells from human newborns. Eur. J. Immunol. 36:21-26.

18. Chiffoleau, E., et al. 2007. TLR9 ligand enhances proliferation of rat $\mathrm{CD} 4+\mathrm{T}$ cell and modulates suppressive activity mediated by CD4+CD25+ T cell. Int. Immunol. 19:193-201.

19. LaRosa, D.F., et al. 2007. CpG DNA inhibits CD4+CD25+ Treg suppression through direct MyD88-dependent costimulation of effector CD4+ T cells. Immunol. Lett. 108:183-188.

20. Deng, G.M., Nilsson, I.M., Verdrengh, M., Collins, L.V., and Tarkowski, A. 1999. Intra-articularly localized bacterial DNA containing CpG motifs induces arthritis. Nat. Med. 5:702-705.

21. Saal, J.G., et al. 1992. Persistence of B19 parvovirus in synovial membranes of patients with rheumatoid arthritis. Rheumatol. Int. 12:147-151.

22. Saal, J.G., et al. 1999. Synovial Epstein-Barr virus infection increases the risk of rheumatoid arthritis in individuals with the shared HLA-DR4 epitope. Arthritis Rheum. 42:1485-1496.

23. Schrijver, I.A., Melief, M.J., Tak, P.P., Hazenberg, M.P., and Laman, J.D. 2000. Antigen-presenting cells containing bacterial peptidoglycan in synovial tissues of rheumatoid arthritis patients coexpress costimulatory molecules and cytokines. Artbritis Rheum. 43:2160-2168.

24. van der Heijden, I., et al. 2000. Presence of bacterial DNA and bacterial peptidoglycans in joints of patients with rheumatoid arthritis and other arthritides. Arthritis Rheum. 43:593-598.

25. Roelofs, M.F., et al. 2006. Identification of small heat shock protein B8 (HSP22) as a novel TLR4 ligand and potential involvement in the pathogenesis of rheumatoid arthritis. J. Immunol. 176:7021-7027.

26. Scott, D.L., Delamere, J.P., and Walton, K.W. 1981. The distribution of fibronectin in the pannus in rheumatoid arthritis. Br. J. Exp. Pathol. 62:362-368.

27. Walle, T.K., Vartio, T., Helve, T., Virtanen, I., and Kurki, P. 1990. Cellular fibronectin in rheumatoid synovium and synovial fluid: a possible factor contributing to lymphocytic infiltration. Scand. J. Immunol. 31:535-540.

28. Iwahashi, M., et al. 2004. Expression of Toll-like receptor 2 on $\mathrm{CD} 16+$ blood monocytes and synovial tissue macrophages in rheumatoid arthritis. Arthritis Rheum. 50:1457-1467.

29. Radstake, T.R., et al. 2004. Expression of toll-like receptors 2 and 4 in rheumatoid synovial tissue and regulation by proinflammatory cytokines interleukin-12 and interleukin-18 via interferon-gamma. Arthritis Rheum. 50:3856-3865.

30. Roelofs, M.F., et al. 2005. The expression of toll-like receptors 3 and 7 in rheumatoid arthritis synovium is increased and costimulation of toll-like receptors 3 , 4 , and $7 / 8$ results in synergistic cytokine production by dendritic cells. Arthritis Rheum. 52:2313-2322.

31. Seibl, R., et al. 2003. Expression and regulation of Toll-like receptor 2 in rheumatoid arthritis synovium. Am. J. Pathol. 162:1221-1227.

32. Sacre, S.M., et al. 2007. The Toll-like receptor adaptor proteins MyD88 and Mal/TIRAP contribute to the inflammatory and destructive processes in a human model of rheumatoid arthritis. Am. J. Pathol. 170:518-525

33. Horai, R., et al. 2000. Development of chronic inflammatory arthropathy resembling rheumatoid arthritis in interleukin 1 receptor antagonist-deficient mice. J. Exp. Med. 191:313-320.

34. Horai, R., et al. 2004. TNF-alpha is crucial for the development of autoimmune arthritis in IL-1 receptor antagonist-deficient mice. J. Clin. Invest.
114:1603-1611.

35. Nakae, S., et al. 2003. IL-17 production from activated $T$ cells is required for the spontaneous development of destructive arthritis in mice deficient in IL-1 receptor antagonist. Proc. Natl. Acad. Sci. U. S. A. 100:5986-5990.

36. Cho, M.L., et al. 2006. STAT3 and NF-kappaB signal pathway is required for IL-23-mediated IL-17 production in spontaneous arthritis animal model IL-1 receptor antagonist-deficient mice. J. Immunol. 176:5652-5661.

37. Yolton, D.P., Stanley, C., and Savage, D.C. 1971. Influence of the Indigenous Gastrointestinal Microbial Flora on Duodenal Alkaline Phosphatase Activity in Mice. Infect. Immun. 3:768-773.

38. Kiura, K., Kataoka, H., Yasuda, M., Inoue, N., and Shibata, K. 2006. The diacylated lipopeptide FSL-1 induces TLR2-mediated Th2 responses. FEMS Immunol. Med. Microbiol. 48:44-55.

39. Gelman, A.E., Zhang, J., Choi, Y., and Turka, L.A. 2004. Toll-like receptor ligands directly promote activated CD4+ T cell survival. J. Immunol. 172:6065-6073.

40. Prinz, M., et al. 2006. Innate immunity mediated by TLR9 modulates pathogenicity in an animal model of multiple sclerosis. J. Clin. Invest. 116:456-464.

41. Re, F., and Strominger, J.L. 2004. IL-10 released by concomitant TLR2 stimulation blocks the induction of a subset of Th1 cytokines that are specifically induced by TLR 4 or TLR 3 in human dendritic cells. J. Immunol. 173:7548-7555.

42. Harrington, L.E., et al. 2005. Interleukin 17-producing CD4+ effector T cells develop via a lineage distinct from the $T$ helper type 1 and 2 lineages. Nat. Immunol. 6:1123-1132.

43. Park, H., et al. 2005. A distinct lineage of CD4 T cells regulates tissue inflammation by producing interleukin 17. Nat. Immunol. 6:1133-1141.

44. Suryani, S., and Sutton, I. 2007. An interferongamma-producing Th1 subset is the major source of IL-17 in experimental autoimmune encephalitis J. Neuroimmunol. 183:96-103.

45. Annunziato, F., et al. 2007. Phenotypic and functional features of human Th17 cells. J. Exp. Med. 204:1849-1861.

46. Fontenot, J.D., et al. 2005. Regulatory T cell lineage specification by the forkhead transcription factor foxp3. Immunity. 22:329-341.

47. Wan, Y.Y., and Flavell, R.A. 2005. Identifying Foxp3-expressing suppressor $\mathrm{T}$ cells with a bicistronic reporter. Proc. Natl. Acad. Sci. U. S. A. 102:5126-5131.

48. Wan, Y.Y., and Flavell, R.A. 2007. Regulatory T-cell functions are subverted and converted owing to attenuated Foxp3 expression. Nature. 445:766-770.

49. Bettelli, E., et al. 2006. Reciprocal developmental pathways for the generation of pathogenic effector TH17 and regulatory T cells. Nature. 441:235-238.

50. Mangan, P.R., et al. 2006. Transforming growth factor-beta induces development of the $\mathrm{T}(\mathrm{H}) 17$ lineage. Nature. 441:231-234.

51. Veldhoen, M., Hocking, R.J., Atkins, C.J., Locksley, R.M., and Stockinger, B. 2006. TGFbeta in the context of an inflammatory cytokine milieu supports de novo differentiation of IL-17-producing T cells. Immunity. 24:179-189.

52. Veldhoen, M., Hocking, R.J., Flavell, R.A., and Stockinger, B. 2006. Signals mediated by transforming growth factor-beta initiate autoimmune encephalomyelitis, but chronic inflammation is needed to sustain disease. Nat. Immunol. 7:1151-1156.

53. Belghith, M., et al. 2003. TGF-beta-dependent mechanisms mediate restoration of self-tolerance induced by antibodies to CD3 in overt autoim- mune diabetes. Nat. Med. 9:1202-1208.

54. Fontenot, J.D., Gavin, M.A., and Rudensky, A.Y 2003. Foxp3 programs the development and function of CD $4+\mathrm{CD} 25+$ regulatory T cells. Nat. Immunol. 4:330-336.

55. Hori, S., Nomura, T., and Sakaguchi, S. 2003. Control of regulatory $\mathrm{T}$ cell development by the transcription factor Foxp3. Science. 299:1057-1061.

56. Joosten, L.A., Helsen, M.M., van de Loo, F.A., and van den Berg, W.B. 1996. Anticytokine treatment of established type II collagen-induced arthritis in $\mathrm{DBA} / 1$ mice. A comparative study using anti-TNF alpha, anti-IL-1 alpha/beta, and IL-1Ra. Arthritis Rheum. 39:797-809.

57. Koenders, M.I., et al. 2005. Blocking of interleukin17 during reactivation of experimental arthritis prevents joint inflammation and bone erosion by decreasing RANKL and interleukin-1. Am. J. Pathol. 167:141-149.

58. Lubberts, E., et al. 2004. Treatment with a neutralizing anti-murine interleukin-17 antibody after the onset of collagen-induced arthritis reduces joint inflammation, cartilage destruction, and bone erosion. Arthritis Rheum. 50:650-659.

59. Joosten, L.A., et al. 2003. Association of interleukin-18 expression with enhanced levels of both interleukin-1beta and tumor necrosis factor alpha in knee synovial tissue of patients with rheumatoid arthritis. Arthritis Rheum. 48:339-347.

60. Chabaud, M., Lubberts, E., Joosten, L.A., van den Berg, W.B., and Miossec, P. 2001. IL-17 derived from juxta-articular bone and synovium contributes to joint degradation in rheumatoid arthritis. Arthritis Res. 3:168-177.

61. Abdollahi-Roodsaz, S., et al. 2007. Inhibition of TLR 4 breaks the inflammatory loop in autoimmune destructive arthritis. Arthritis Rheum. 56:2957-2967.

62. Park, J.S., et al. 2004. Involvement of toll-like receptors 2 and 4 in cellular activation by high mobility group box 1 protein. J. Biol. Chem. 279:7370-7377.

63. Vabulas, R.M., et al. 2002. The endoplasmic reticulum-resident heat shock protein Gp96 activates dendritic cells via the Toll-like receptor $2 / 4$ pathway. J. Biol. Chem. 277:20847-20853.

64. Prince, J.M., et al. 2006. Toll-like receptor-4 signaling mediates hepatic injury and systemic inflammation in hemorrhagic shock. J. Am. Coll. Surg. 202:407-417.

65. Tsung, A., et al. 2005. The nuclear factor HMGB1 mediates hepatic injury after murine liver ischemiareperfusion. J. Exp. Med. 201:1135-1143.

66. Zhai, Y., et al. 2004. Cutting edge: TLR4 activation mediates liver ischemia/reperfusion inflammatory response via IFN regulatory factor 3-dependent MyD88-independent pathway. J. Immunol. 173:7115-7119

67. Nicklin, M.J., Hughes, D.E., Barton, J.L., Ure, J.M., and Duff, G.W. 2000. Arterial inflammation in mice lacking the interleukin 1 receptor antagonist gene. J. Exp. Med. 191:303-312.

68. Jonuleit, H., et al. 1997. Pro-inflammatory cytokines and prostaglandins induce maturation of potent immunostimulatory dendritic cells under fetal calf serum-free conditions. Eur. J. Immunol. 27:3135-3142.

69. van de Loo, F.A., Arntz, O.J., Otterness, I.G., and van den Berg, W.B. 1992. Protection against cartilage proteoglycan synthesis inhibition by antiinterleukin 1 antibodies in experimental arthritis. J. Rheumatol. 19:348-356.

70. Gearing, A.J., Bird, C.R., Bristow, A., Poole, S., and Thorpe, R. 1987. A simple sensitive bioassay for interleukin-1 which is unresponsive to $10(3) \mathrm{U} / \mathrm{ml}$ of interleukin-2. J. Immunol. Methods. 99:7-11. 